Article

\title{
Analysis of Spatio-temporal Characteristics and Driving Forces of Air Quality in the Northern Coastal Comprehensive Economic Zone, China
}

\author{
Ying Su ${ }^{1,2,3,+}$, Chunyan Lu ${ }^{1,2,3, *,+\oplus}$, Xiaoqing Lin ${ }^{1}$, Lianxiu Zhong ${ }^{1}$, Yibin Gao ${ }^{1}$ and Yifan Lei ${ }^{1}$ \\ 1 College of Computer and Information Sciences, Fujian Agriculture and Forestry University, Fuzhou 350002, \\ China; suying@fafu.edu.cn (Y.S.); xq_lin@fafu.edu.cn (X.L.); lxzhong@fafu.edu.cn (L.Z.); \\ Gao_YB@fafu.edu.cn (Y.G.); leiyf@fafu.edu.cn (Y.L.) \\ 2 Key Laboratory of Ecology and Resources Statistics of Fujian Province Universities, Fujian Agriculture and \\ Forestry University, Fuzhou 350002, China \\ 3 Research Centre of Resource and Environment Spatial Information Statistics of Fujian Province, Fujian \\ Agriculture and Forestry University, Fuzhou 350002, China \\ * Correspondence: luchunyan@fafu.edu.cn; Tel.: +86-137-6380-5686 \\ + These authors contributed equally to this work.
}

Received: 26 November 2019; Accepted: 8 January 2020; Published: 10 January 2020

\begin{abstract}
Comprehensive analysis of air quality is essential to underpin knowledge-based air quality conservation policies and funding decisions by governments and managers. In this paper, air quality change characteristics for the Northern Coastal Comprehensive Economic Zone from 2008 to 2018 were analyzed using air quality indices. The spatio-temporal pattern of air quality was identified using centroid migration, spatial autocorrelation analysis and spatial analysis in a geographic information system (GIS). A spatial econometric model was established to confirm the natural and anthropogenic factors affecting air quality. Results showed that air pollution decreased significantly. $\mathrm{PM}_{2.5}, \mathrm{PM}_{10}$, and $\mathrm{O}_{3}$ were the primary pollutants. The air quality exhibited an inverted U-shaped trend from January to December, with the highest quality being observed in summer and the lowest during winter. Spatially, the air quality showed an increasing trend from inland to the coast and from north to south, with significant spatial autocorrelation and clustering. Population, energy consumption, temperature, and atmospheric pressure had significant negative impacts on air quality, while wind speed had a positive impact. This study offers an efficient and effective method to evaluate air quality change. The research provides important scientific information necessary for developing future air pollution prevention and control.
\end{abstract}

Keywords: air quality; Northern Coastal Comprehensive Economic Zone; spatio-temporal evolution; spatial autocorrelation; spatial econometric model

\section{Introduction}

Air pollution has become the single largest environmental health risk, causing about 7 million deaths around the world in 2012 [1]. Owing to the frequency and perniciousness of air pollution incidents, air pollution has attracted increasing attention as a regional and global environmental issue [2]. People's daily lives, especially physical health, are affected by air pollution problems, which has aroused social dissatisfaction and unrest [3]. Air pollution has become the fourth greatest risk factor in all deaths after heart attacks, dietary conditions and smoking in China [4]. Poor air quality causes an estimated 2.6-4.8 million premature deaths per year worldwide [5,6]. Considerable evidence has shown that other health issues, such as asthma, respiratory and cardiovascular diseases, are related to air pollution [7]. As air pollution leads to a series of health problems, outdoor sports in bad air 
quality would offset the health benefits of physical activities to some extent [8]. Thus, media alerts and warnings of poor air quality may alter people's decisions on spending time outdoors and engaging in physical activity [9]. In addition, worsening air pollution has affected sustainable socio-economic development. According to a new Organization for Economic Co-operation and Development (OECD) report, unless action is taken, substantial problems (including sick days, medical bills and reduced agricultural output) caused by outdoor air pollution will cost $1 \%$ of global Gross Domestic Product (GDP) per year by 2060 [10]. In 2013, North China experienced a persistent and extensive haze-fog pollution, affecting the health of more than 800 million people and causing economic losses valued at approximately 23 billion Yuan (about 4 billion US dollar) [11]. Faced with serious local, regional, and transboundary impacts caused by increasing unregulated air pollution, there is an urgent need to analyze the distribution and characteristics of air pollution and identify the driving factors. This analysis will help policymakers formulate effective regulations to reduce air pollution and develop long-term strategies for air quality conservation.

Previous studies on air quality concentrated on individual air pollutants [12-14]. The prominent impacts of $\mathrm{PM}_{10}$ and $\mathrm{PM}_{2.5}$ on human health and the atmospheric environment have made them a focus of research. For example, the spatio-temporal pattern of $\mathrm{PM}_{10}$ and $\mathrm{PM}_{2.5}$ was quantitatively analyzed in Taiwan, and the industrial and urban areas were found to have high $\mathrm{PM}_{10}$ and $\mathrm{PM}_{2.5}$ concentrations [15]. By analyzing the spatio-temporal distribution of $\mathrm{PM}_{2.5}$ and $\mathrm{O}_{3}$ and their interactions in Beijing, Zhao et al. inferred that the content of $\mathrm{PM}_{2.5}$ and $\mathrm{O}_{3}$ in air showed a positive correlation in summer and a negative correlation in winter [16]. $\mathrm{SO}_{2}$ and $\mathrm{NO}_{2}$ were used as denotative indicators to assess the air quality in northwest Turkey: the results showed that the two pollutants could reflect the degree of pollution effectively [17]. Nevertheless, due to the complexity of air pollution, air quality status cannot be reflected comprehensively using only one or two air pollutants. In recent years, some comprehensive evaluation indices based on examining and weighing pollutants have been used in the assessment and analysis of air quality. North America uses the Air Quality Health Index (AQHI) as an integrated index to revealing where the air pollutants are most frequently present and what risks they pose to human health [18]. Air quality changes were quantified using the Comprehensive Air Quality Index (CAQI) in China and California, respectively, and the spatio-temporal dynamics of air pollutants were examined $[19,20]$. Although assessment criteria are provided by several comprehensive evaluation indices of air quality, the related research focuses on the spatio-temporal distribution trends of air pollution. Pseudo-AQHI is used to analyze the seasonal variation of air pollution in a city of Canada, and the relationship between school location, active transportation and air pollution was explored by exploratory spatial analysis methods [21]. Daily and monthly changes of air quality were distinguished and evaluated through the Air Quality Index (AQI) in Beijing [22]. Additionally, there are few studies on the changes in the type of air pollutants and the driving factors of air quality $[23,24]$. Thus, it is informative to study these factors in detail. This knowledge will help determine how air quality dynamics are driven by diverse pollutants, develop optimal control measures of air pollution, and provide references for future air quality studies $[25,26]$.

As one of the eight economic zones in China, the Northern Coastal Comprehensive Economic Zone (NCCEZ) has experienced severe air pollution for many years. Accordingly, a comprehensive understanding of the spatio-temporal dynamics and variations in air quality is crucial for developing specific and effective measures of air quality improvement. This research aims to provide scientific evidence for new policy proposals to improve the NCCEZ's air quality. We collected long-term air quality monitoring data to investigate the spatio-temporal change characteristics in the NCCEZ. Specifically, we (1) present the spatio-temporal variations of air quality to examine the air pollution levels, (2) explore the change of primary pollutants in each city to disclose air quality conditions, and (3) identify the effect and interactions of driving factors impacting on the spatial disparity of air quality using spatial econometric models. 


\section{Materials and Methods}

\subsection{Study Area}

The NCCEZ is located west of the Bohai Sea and the Yellow Sea, in China. The latitude ranges from $34.22^{\circ} \mathrm{N}$ to $42.40^{\circ} \mathrm{N}$ and the longitude ranges from $113.27^{\circ} \mathrm{E}$ to $122.42^{\circ} \mathrm{E}$, with a total area of 0.04 million $\mathrm{km}^{2}$ and a total population of about 0.21 billion. It consists of four provinces, Beijing, Tianjin, Hebei and Shandong, which include 30 prefecture-level administrative cities (Figure 1 and Table 1). The prevalent climate of this region is a mid-latitude monsoon climate, characterized by a cold and dry winter and hot and rainy summer. The average annual precipitation is $500-1000 \mathrm{~mm}$, up to $80 \%$ of which falls from June to August. The landform is dominated by plains, and the elevation gradually decreases from northwest to southeast.

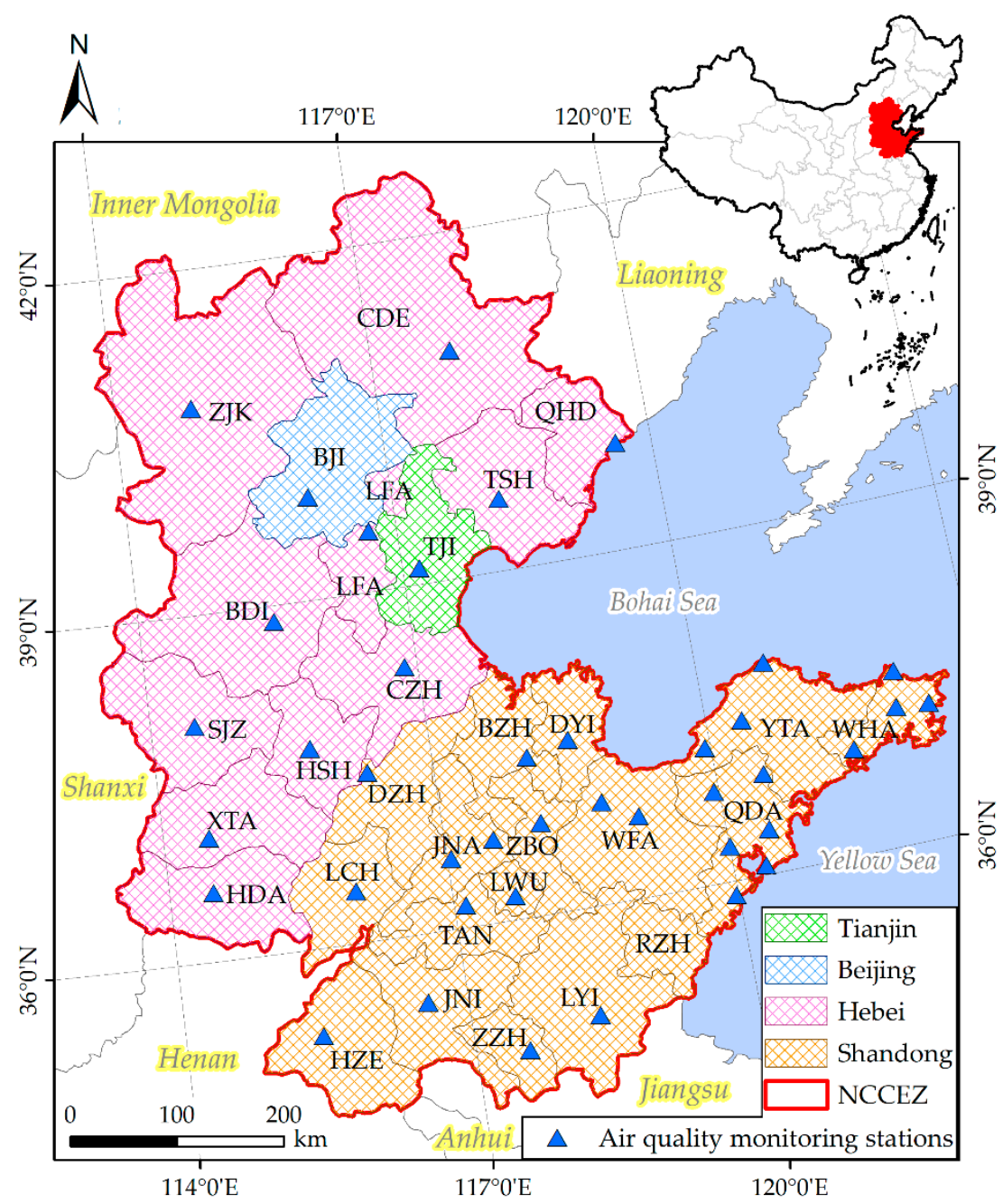

Figure 1. Location of the study area (NCCEZ: the Northern Coastal Comprehensive Economic Zone, BDI: Baoding city, BJI: Beijing city, BZH: Binzhou city, CZH: Cangzhou city, CDE: Chengde city, DZH: Dezhou city, DYI: Dongying city, HDA: Handan city, HZE: Heze city, HSH: Hengshui city, JNA: Jinan city, JNI: Jining city, LWU: Laiwu city, LFA: Langfang city, LCH: Liaocheng city, LYI: Linyi city, QHD: Qinhuangdao city, QDA: Qingdao city, RZH: Rizhao city, SJZ: Shijiazhuang city, TAN: Tai'an city, TSH: Tangshan city, TJI: Tianjin city, WHA: Weihai city, WFA: Weifang city, XTA: Xingtai city, YTA: Yantai city, ZZH: Zaozhuang city, ZJK: Zhangjiakou city and ZBO: Zibo city). 
Table 1. Basic information description of each city in NCCEZ.

\begin{tabular}{|c|c|c|c|c|c|}
\hline Name & Municipality or Province & Area(Thousand $\mathrm{km}^{2}$ ) & Population(Million Person) & GDP(Trillion-Yuan) & Code \\
\hline Beijing & Beijing & 16.41 & 2.15 & 3.03 & BJI \\
\hline Baoding & Hebei & 22.19 & 0.94 & 0.31 & BDI \\
\hline Cangzhou & Hebei & 14.00 & 0.76 & 0.37 & $\mathrm{CZH}$ \\
\hline Chengde & Hebei & 39.52 & 0.38 & 0.15 & $\mathrm{CDE}$ \\
\hline Handan & Hebei & 12.07 & 0.95 & 0.35 & HDA \\
\hline Hengshui & Hebei & 8.82 & 0.46 & 0.16 & $\mathrm{HSH}$ \\
\hline Langfang & Hebei & 6.43 & 0.48 & 0.31 & LFA \\
\hline Qinhuangdao & Hebei & 7.81 & 0.31 & 0.16 & QHD \\
\hline Shijiazhuang & Hebei & 14.46 & 1.1 & 0.61 & SJZ \\
\hline Tangshan & Hebei & 13.47 & 0.79 & 0.65 & TSH \\
\hline Xingtai & Hebei & 12.40 & 0.8 & 0.22 & XTA \\
\hline Zhangjiakou & Hebei & 36.80 & 0.47 & 0.15 & ZJK \\
\hline Binzhou & Shandong & 9.45 & 0.23 & 0.26 & $\mathrm{BZH}$ \\
\hline Dezhou & Shandong & 10.36 & 0.58 & 0.34 & $\mathrm{DZH}$ \\
\hline Dongying & Shandong & 8.24 & 0.22 & 0.4 & DYI \\
\hline Heze & Shandong & 12.24 & 0.88 & 0.31 & HZE \\
\hline Jinan & Shandong & 10.24 & 0.75 & 0.79 & JNA \\
\hline Jining & Shandong & 11.19 & 0.84 & 0.49 & JNI \\
\hline Laiwu & Shandong & 1.74 & 0.14 & 0.09 & LWU \\
\hline Liaocheng & Shandong & 8.72 & 0.61 & 0.32 & $\mathrm{LCH}$ \\
\hline Linyi & Shandong & 17.19 & 1.06 & 0.47 & LYI \\
\hline Qingdao & Shandong & 11.28 & 0.94 & 1.2 & QDA \\
\hline Rizhao & Shandong & 5.36 & 0.94 & 0.22 & $\mathrm{RZH}$ \\
\hline Tai'an & Shandong & 7.76 & 0.56 & 0.36 & TAN \\
\hline Weihai & Shandong & 5.80 & 0.28 & 0.36 & WHA \\
\hline Weifang & Shandong & 15.86 & 0.94 & 0.62 & WFA \\
\hline Yantai & Shandong & 13.75 & 0.7 & 0.78 & YTA \\
\hline Zaozhuang & Shandong & 4.56 & 0.42 & 0.24 & $\mathrm{ZZH}$ \\
\hline Zibo & Shandong & 5.97 & 0.47 & 0.51 & $\mathrm{ZBO}$ \\
\hline Tianjin & Tianjin & 11.92 & 1.56 & 1.88 & TJI \\
\hline
\end{tabular}

Industrialization, convenient transport networks, and abundant natural resources have led to the economic development of the NCCEZ. As one of the most powerful high-tech research and development areas and manufacturing centers in China, the NCCEZ is becoming a comprehensive economic zone with global influence. In 2018, the GDP of the region had reached 16.16 trillion Yuan, accounting for $17.95 \%$ of China's GDP.

\subsection{Data Sources and Pre-Processing}

Air quality monitoring data, including the daily air quality index, primary pollutants, and air quality level, from 2008 to 2018, were collected from 41 air quality observation stations in or around the NCCEZ. The data were provided by the Ministry of Ecology and Environment of the People's Republic of China. It is noted that there are two air quality indices to evaluate the air conditions, the Air Pollution Index (API) and the AQI: the higher their value, the lower the air quality. These two indices are calculated from the sub-index of each air pollutant, and the maximum value of all sub-indices is defined as the API or AQI as follows [27]:

$$
\begin{gathered}
\mathrm{API}=\max \left\{I_{\left.A P I_{\mathrm{SO}_{2}}, I A P I_{\mathrm{NO}_{2}}, I A P I_{\mathrm{PM}_{10}}\right\}}\right. \\
\mathrm{AQI}=\max \left\{I A Q I_{\mathrm{SO}_{2}}, I A Q I_{\mathrm{NO}_{2}}, I A Q I_{\mathrm{PM}_{10}}, I A Q I_{P_{2.5}}, I A Q I_{\mathrm{O}_{3}}, I A Q I_{\mathrm{CO}}\right\}
\end{gathered}
$$

where IAPI and IAQI represent the sub-indices of API and AQI, respectively, and are calculated as follows [27]:

$$
I_{p}=\frac{I_{h}-I_{l}}{B_{h}-B_{l}}\left(C_{p}-B_{l}\right)+I_{l}
$$

where $I_{p}$ is IAPI or IAQI of pollutant $p, C_{p}$ is the concentration of pollutant $p, B_{h}$ and $B_{l}$ represent the upper and lower limits for pollutants corresponding to $C_{p}$, respectively. $I_{h}$ represents the IAPI or $I A Q I$ corresponding to $B_{h}$, and $I_{l}$ represents the IAPI or IAQI corresponding to $B_{l}$. The evaluation criteria of the AQI are more accurate and comprehensive than those of the API, because they assess more pollutant types (Table 2). Due to different evaluation standards, the two indices should not be 
compared at the same level. Therefore, the research time of the study was divided into two stages: 2008-2012 and 2013-2018, using the API and AQI, respectively. The primary pollutant refers to the one that accounts for the largest percentage of air pollution.

Table 2. Detailed information on Air Pollution Index (API) and Air Quality Index (AQI).

\begin{tabular}{|c|c|c|c|c|c|c|}
\hline Name & $\begin{array}{l}\text { Application } \\
\text { Time Range }\end{array}$ & $\begin{array}{c}\text { Evaluated } \\
\text { Pollutant Type }\end{array}$ & $\begin{array}{c}\text { Environmental } \\
\text { Quality Standard }\end{array}$ & $\begin{array}{c}\text { Value } \\
\text { Range }\end{array}$ & $\begin{array}{c}\text { Air Quality } \\
\text { Rank }\end{array}$ & Air Quality Condition \\
\hline API & $\begin{array}{c}\text { From } 1996 \text { to } \\
2012\end{array}$ & $\mathrm{SO}_{2}, \mathrm{NO}_{2}, \mathrm{PM}_{10}$ & GB3095-1996 [28] & $\begin{array}{c}0-50 \\
51-100 \\
101-150 \\
151-200 \\
201-250 \\
251-300 \\
>300\end{array}$ & $\begin{array}{c}\text { Class I } \\
\text { Class II } \\
\text { Class III }_{(1)} \\
\text { Class III }_{(2)} \\
\text { Class IV }_{(1)} \\
\text { Class IV }_{(2)} \\
\text { Class VI }\end{array}$ & $\begin{array}{c}\text { Excellent } \\
\text { Fine } \\
\text { Slight pollution } \\
\text { Mild pollution } \\
\text { Medium pollution } \\
\text { Medium Heavy pollution } \\
\text { Heavy pollution }\end{array}$ \\
\hline AQI & $\begin{array}{c}\text { From } 2013 \text { to } \\
\text { present }\end{array}$ & $\begin{array}{c}\mathrm{SO}_{2}, \mathrm{NO}_{2}, \mathrm{PM}_{10} \\
\mathrm{PM}_{2.5}, \mathrm{O}_{3}, \mathrm{CO}\end{array}$ & GB3095-2012 [29] & $\begin{array}{c}0-50 \\
51-100 \\
101-150 \\
151-200 \\
201-300 \\
>300\end{array}$ & $\begin{array}{l}\text { Class I } \\
\text { Class II } \\
\text { Class III } \\
\text { Class IV } \\
\text { Class V } \\
\text { Class VI }\end{array}$ & $\begin{array}{c}\text { Excellent } \\
\text { Fine } \\
\text { Slight pollution } \\
\text { Medium pollution } \\
\text { Heavy pollution } \\
\text { Serious pollution }\end{array}$ \\
\hline
\end{tabular}

Note: GB indicates national standard of China.

The monthly average data obtained from air quality monitoring stations were spatially discrete and were interpolated to obtain a spatially continuous surface. According to the applicable conditions of different interpolation methods and the statistical characteristics of air quality data [30,31], a comparison of various interpolation methods was carried out and found that spatially continuous surfaces obtained by ordinary kriging interpolation were optimal. Table 3 shows the error evaluation results by ordinary kriging interpolation. We used the monthly average data to obtain the seasonal average and the annual average. It should be noted that seasons are divided into spring, summer, autumn, and winter, which run from March to May, from June to August, from September to November and from December to February of the following year, respectively [32].

Table 3. Ordinary kriging interpolation error analysis.

\begin{tabular}{ccccc}
\hline Index & $\begin{array}{c}\text { Mean Absolute } \\
\text { Error (MAE) }\end{array}$ & $\begin{array}{c}\text { Mean Relative } \\
\text { Error (MRE) }\end{array}$ & $\begin{array}{c}\text { Root Mean Squared } \\
\text { Error (RMSE) }\end{array}$ \\
\hline \multirow{4}{*}{ API } & Annual & 4.79 & 0.07 & 5.85 \\
& Spring & 5.46 & 0.07 & 6.88 \\
& Summer & 6.27 & 0.11 & 7.31 \\
& Autumn & 3.79 & 0.06 & 4.85 \\
\multirow{4}{*}{ AQI } & Winter & 3.62 & 0.04 & 4.34 \\
& Annual & 4.36 & 0.05 & 5.53 \\
& Spring & 4.83 & 0.05 & 6.33 \\
& Summer & 7.63 & 0.08 & 9.27 \\
& Autumn & 4.78 & 0.06 & 6.26 \\
\hline
\end{tabular}

To comprehensively analyze the factors influencing the spatio-temporal distribution characteristics of air quality, several variables were selected which reflect natural and anthropogenic impacts [33-35]. Natural variables included six factors, i.e., elevation, wind speed, precipitation, temperature, atmospheric pressure, and Normalized Difference Vegetation Index (NDVI). The NDVI was obtained from the MODIS 'Vegetation Indices 16-Day L3 Global 250 m' product (hereinafter 'MOD13Q1') [36]. Other data were collected from the National Meteorological Information Center [37]. Another six variables, i.e., population, urban land area, GDP, ratio of secondary industry, civilian car ownership and energy consumption, were chosen as anthropogenic factors. The civilian car ownership was obtained from the China Statistical Yearbook for Regional Economy and the China Statistical Yearbook of Tertiary 
Industry [38,39], and the remaining data were derived from the China City Statistical Yearbook [40]. Details of each variable influencing air quality are given in Table 4.

Table 4. Detailed information on each variable influencing air quality.

\begin{tabular}{|c|c|c|c|}
\hline & cator & Unit & Data Sources \\
\hline \multirow{7}{*}{ Anthropogenic variables } & Population & person & China City Statistical Yearbook [40] \\
\hline & Urban land area & $\mathrm{km}^{2}$ & China City Statistical Yearbook [40] \\
\hline & GDP & yuan & China City Statistical Yearbook [40] \\
\hline & Ratio of secondary industry & $\%$ & China City Statistical Yearbook [40] \\
\hline & & & China Statistical Yearbook for \\
\hline & Civilian car ownership & unit & $\begin{array}{c}\text { Regional Economy and China } \\
\text { Statistical Yearbook of the Tertiary } \\
\text { Industry }[38,39]\end{array}$ \\
\hline & Energy consumption & $\begin{array}{l}\text { Ten thousand tons of } \\
\text { standard coal }\end{array}$ & China City Statistical Yearbook [40] \\
\hline \multirow{6}{*}{ Natural variables } & Elevation & $\mathrm{m}$ & $\begin{array}{l}\text { National Meteorological } \\
\text { Information Center [37] }\end{array}$ \\
\hline & Wind speed & $\mathrm{m} / \mathrm{s}$ & $\begin{array}{l}\text { National Meteorological } \\
\text { Information Center [37] }\end{array}$ \\
\hline & Precipitation & $\mathrm{mm}$ & $\begin{array}{l}\text { National Meteorological } \\
\text { Information Center [37] }\end{array}$ \\
\hline & Temperature & ${ }^{\circ} \mathrm{C}$ & $\begin{array}{l}\text { National Meteorological } \\
\text { Information Center [37] }\end{array}$ \\
\hline & Atmospheric pressure & $\mathrm{kPa}$ & $\begin{array}{l}\text { National Meteorological } \\
\text { Information Center [37] }\end{array}$ \\
\hline & NDVI & - & $\begin{array}{l}\text { National Aeronautics and Space } \\
\text { Administration [36] }\end{array}$ \\
\hline
\end{tabular}

\subsection{Spatial Autocorrelation Analysis}

To determine the spatial clustering pattern of air quality, the global Moran's I index was used to describe the degree of global autocorrelation of air quality. The local Moran's I index was used to calculate the correlation between the air quality of one city and its neighboring cities. The formula of the global Moran's I index and the local Moran's I index are expressed as [41,42]:

$$
\begin{gathered}
I_{G}=\frac{n \sum_{i=1}^{n} \sum_{j=1}^{n} W_{i j}\left(x_{i}-\bar{x}\right)\left(x_{j}-\bar{x}\right)}{\left(\sum_{i=1}^{n} \sum_{j=1}^{n} W_{i j}\right) \sum_{i=1}^{n}\left(x_{i}-\bar{x}\right)^{2}},(i \neq j) \\
I_{L}=\frac{n\left(x_{i}-\bar{x}\right) \sum_{j=1}^{n} W_{i j}\left(x_{j}-\bar{x}\right)}{\sum_{i=1}^{n}\left(x_{i}-\bar{x}\right)^{2}},(i \neq j)
\end{gathered}
$$

where $I_{G}$ is the global Moran's $I$ index, $I_{L}$ is the local Moran's $I$ index, $x_{i}$ and $x_{j}$ are the observed values of the air quality index in the $i$ th and $j$ th city, $\bar{x}$ is the average value of the air quality index for all cities, $n$ is the total number of cities in the study area, and $W_{i j}$ is the spatial weight between cities, i.e., when the two cities share a border, $W_{i j}$ is equal to 1 , otherwise, $W_{i j}$ is 0 . The value of $I_{G}$ ranges from -1 to 1 , and the higher the absolute value, the stronger the spatial agglomeration. A significant and positive $I_{G}$ indicates a clustering pattern with similar air quality, and a significant and negative value suggests a clustering pattern with dissimilar air quality, while an $I_{G}$ of 0 indicates no spatial autocorrelation. Based on the value of $I_{L}$, the spatial association modes of local autocorrelation can be defined into four types: high-high clustering type (hereinafter $\mathrm{HH}$ ), low-high clustering type (LH), low-low clustering type (LL) and high-low clustering type (HL). The HH and LL exhibit positive spatial autocorrelation, i.e., cities with low air quality cluster spatially and cities with high air quality cluster spatially, respectively. The LH and HL exhibit negative autocorrelation, i.e., cities with high air quality surrounded by cities with low air quality and cities with low air quality surrounded by cities with high air quality, respectively. 


\subsection{Spatial Efficiency}

In order to determine the spatial distribution pattern, a novel spatial performance metric denoted Spatial Efficiency (SPAEF) was used, which takes several dimensions of spatial information simultaneously into consideration while the spatial similarity is quantified. The SPAEF is calculated using the following formula [43]:

$$
\begin{gathered}
\text { SAPAEF }=1-\sqrt{(\alpha-1)^{2}+(\beta-1)^{2}+(\gamma-1)^{2}} \\
\alpha=\rho(o b s, \text { sim }) \\
\beta=\left(\frac{\sigma_{\text {sim }}}{\mu_{\text {sim }}}\right) /\left(\frac{\sigma_{o b s}}{\mu_{o b s}}\right) \\
\gamma=\frac{\sum_{j=1}^{n} \min \left(K_{j}, L_{j}\right)}{\sum_{j=1}^{n} K_{j}}
\end{gathered}
$$

where $\alpha$ is the Pearson correlation coefficient between the $z$ th (obs) air quality index pattern and the $j$ th (sim) air quality index pattern, $\beta$ is the fraction of the coefficient of variation (CV) representing spatial variability, $\gamma$ is the histogram intersection for the given histogram $K$ of the $z$ th (obs) air quality index pattern and the histogram $L$ of the $j$ th (sim) air quality index pattern, each containing $n$ bins. In order to enable the comparison of two variables with different units and to ensure bias insensitivity, the $z$ score of the patterns is used to compute $\gamma$. In the study, $\alpha$ is referred to as correlation, $\beta$ as CV ratio and $\gamma$ as histo match.

\subsection{Calculation of Centroid Migration}

The centroid migration of certain attributes can reflect their development characteristics on a spatio-temporal scale [44]. To analyze the spatio-temporal change (direction and distance) characteristics of air quality quantitatively, a weighted average model was used to calculate the centroid migration in the study period. The equation of centroid is expressed as follows [45]:

$$
\mathrm{X}_{t}=\frac{\sum_{i=1}^{n} x_{i} \lambda_{i}}{\sum_{i=1}^{n} \lambda_{i}}, \mathrm{Y}_{t}=\frac{\sum_{i=1}^{n} \mathrm{y}_{i} \lambda_{i}}{\sum_{i=1}^{n} \lambda_{i}}
$$

where $X_{t}$ and $Y_{t}$ represent the latitude and longitude coordinates of the centroid for the observed values of air quality index in the $t$ th year, respectively, $x_{i}$ and $y_{i}$ are the east-west and north-south coordinates of point $i$, respectively, $\lambda_{i}$ represents the observed values of air quality index of the $i$ th point in the $t$ year, and $n$ is the total number of points in the study area.

\subsection{Spatial Econometric Models}

The quantitative relationship between air quality and natural as well as anthropogenic influences were assessed with a spatial econometric model in the study area. Generally, there are two types of spatial econometric models, i.e., spatial lag model (SLM) and spatial error model (SEM). To determine the optimal model, the Lagrange Multiplier (LM) test and the robust LM test were used as evaluation criteria [46]. If the LM lag is statistically more significant than the LM error, and the robust LM lag is statistically more significant than the robust LM error, then SLM is considered as the optimal model, otherwise, the SEM is better.

The expression based on the SLM can be written as [47]:

$$
Y=\rho W Y+\beta X+\varepsilon
$$


where $Y$ denotes a vector of the dependent variable, i.e., the observed values of the air quality index, $X$ denotes a matrix of the explanatory variables, i.e., natural and anthropogenic variables of air quality, $\rho$ is the spatial regression coefficient, $W$ is the spatial weight matrix, $\beta$ is a vector of the parameters, and $\varepsilon$ is a vector of disturbance terms.

The formula based on the SEM is as follows [47]:

$$
\left\{\begin{array}{c}
Y=\beta X+\varepsilon \\
\varepsilon=\lambda W \varepsilon+\mu
\end{array}\right.
$$

where $Y$ denotes a vector of the dependent variable, i.e., the observed values of the air quality index, $X$ denotes a matrix of the explanatory variables, i.e., natural and anthropogenic variables of air quality, $\beta$ is a vector of the parameters, $\varepsilon$ is a vector of disturbance terms, $\lambda$ denotes the spatial autocorrelation coefficient on the error terms, $W$ is the spatial weight matrix, and $\mu$ is an independent and identically distributed residual.

\section{Results}

\subsection{Variation of Air Quality}

The monthly variations of air quality indices in the NCCEZ from 2008 to 2018 are illustrated in Figure 2. The monthly average of API and AQI showed a U-shaped trend of first decreasing and then rising. Specifically, the monthly averages of API and AQI both showed a decreasing trend from January to a minimum value of API in August and a minimum value of AQI in September. Afterward, both gradually increased. In contrast, the monthly change of air quality level presented an inverted U-shaped trend. Between 2008 and 2012, 95\% of days in July and August had excellent and fine air quality, while in January and December over 20\% were air pollution days. Between 2013 and 2018, the number of days with excellent and fine air quality reached more than 60\% in August and September, and the air pollution days reached almost $60 \%$ in January. Overall, the air quality in July, August and September was better than that of other months, and the air quality in January and December was worse than other months.

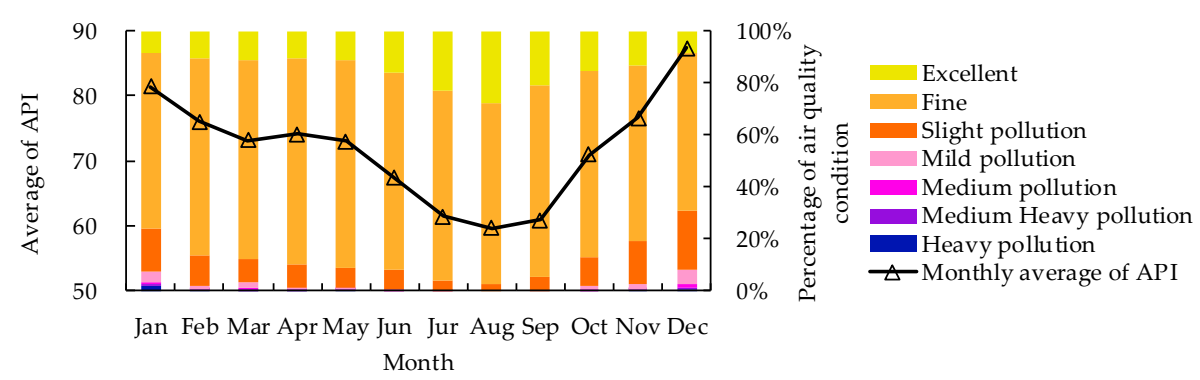

(a)

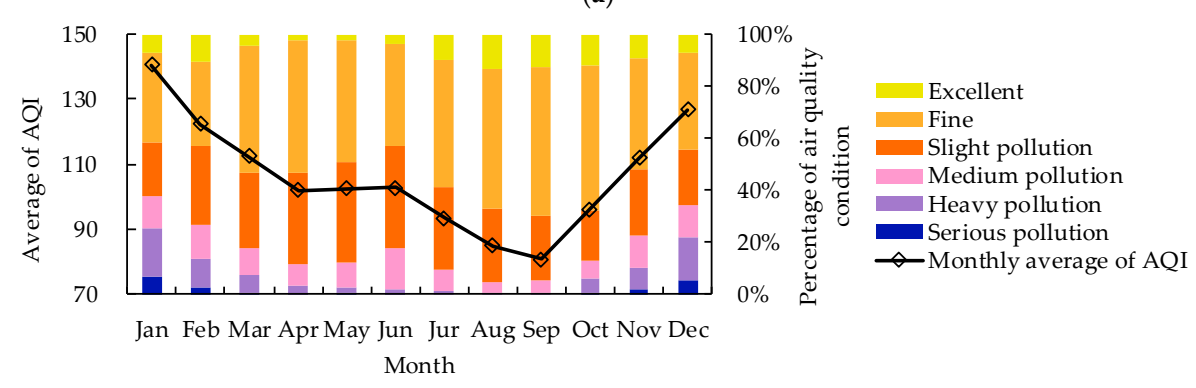

(b)

Figure 2. Monthly variation trend of air quality indices from 2008 to 2018. (a) Monthly average variation of API from 2008 to 2012, (b) Monthly average variation of AQI from 2013 to 2018. 
The seasonal variations of air quality indices are shown in Figure 3. The API and AQI both changed direction in summer, and the value of air quality indices decreased greatly from winter to summer, reaching the lowest value in summer. After summer, the value of air quality indices showed a gradually increasing trend. The results show the change of air quality indices in the seasons, with the mean ranked in a decreasing order as winter (82) > spring (73) > autumn (69) $>$ summer (63) from 2008 to 2012 and winter (130) > spring (106) > autumn (96) > summer (94) from 2013 to 2018. It can be inferred that the air quality was worst in winter and best in summer from 2008 to 2018.

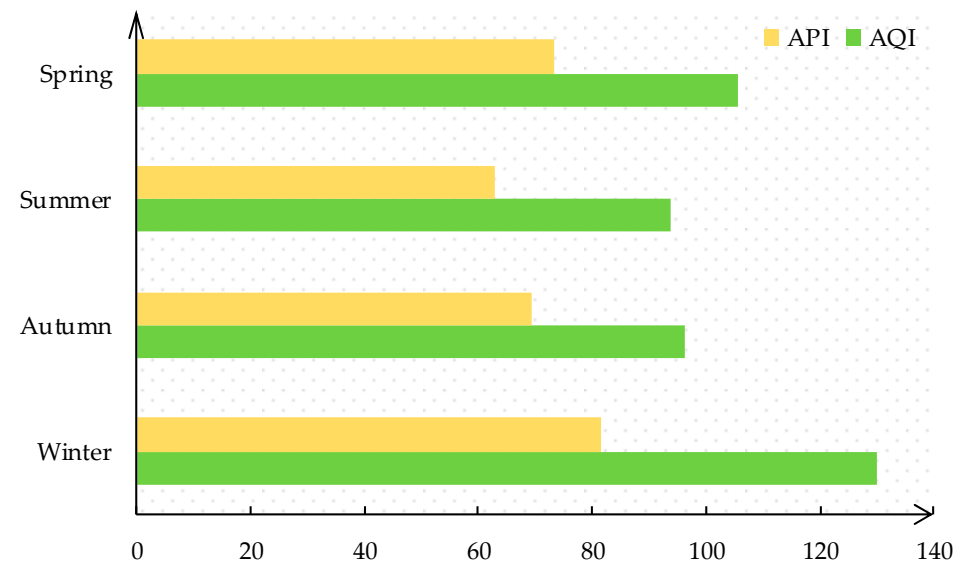

Figure 3. Seasonal variation trend of two air quality indices.

As shown in Figure 4, the annual average change of both API and AQI had a significant downward trend. The annual average value of API declined from 73 in 2008 to 70 in 2012, and the annual average value of AQI declined from 120 in 2013 to 95 in 2018. The highest inter-annual decrease was $9 \%$, which occurred from 2014 to 2015 . This indicated that the air quality of the NCCEZ was gradually improving.

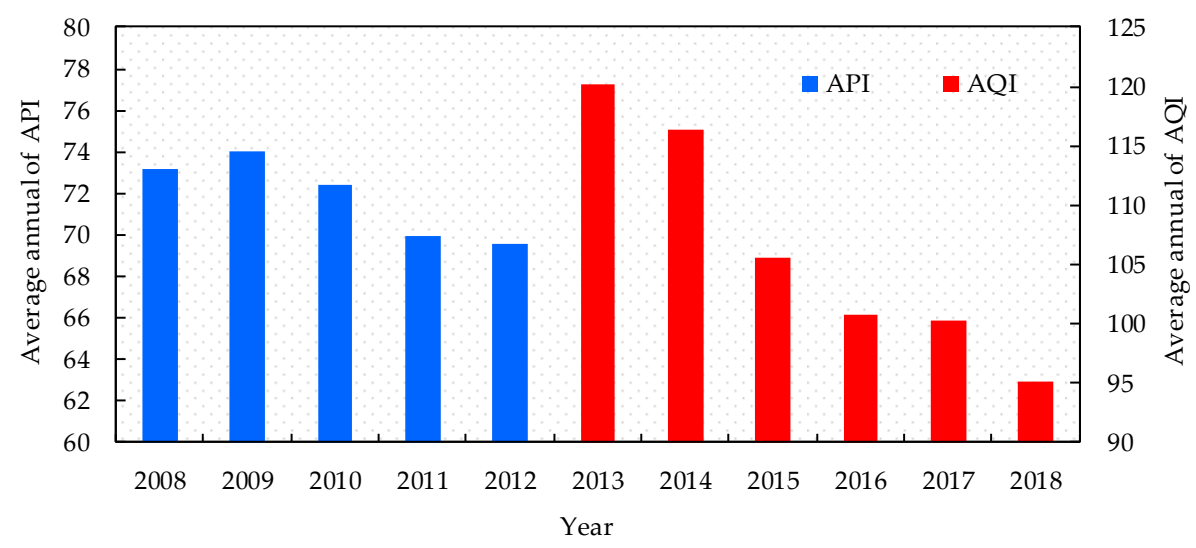

Figure 4. Annual average variation trend of API and AQI.

\subsection{Spatio-Temporal Variation of Air Quality}

Figure 5 illustrates the spatial distribution pattern of air quality indices in different seasons. During the period 2008-2018, the spatial gradient of air quality only changed a little in summer in NCCEZ, and the spatial differentiation of air quality was not obvious. In spring, autumn and winter, however, the spatial gradient of air quality changed significantly, and the spatial differentiation was noticeable. Figure 6 details the spatial distribution of air quality indices for the years 2008, 2010, 2012, 2013,2015 , and 2018. In the study area, the value of air quality increased gradually from inland to coastal areas and from north to south, showing a significant spatial variation. Additionally, the value 
of air quality indices presented a gradual decline in time, suggesting improving air quality for each city from 2008 to 2018.
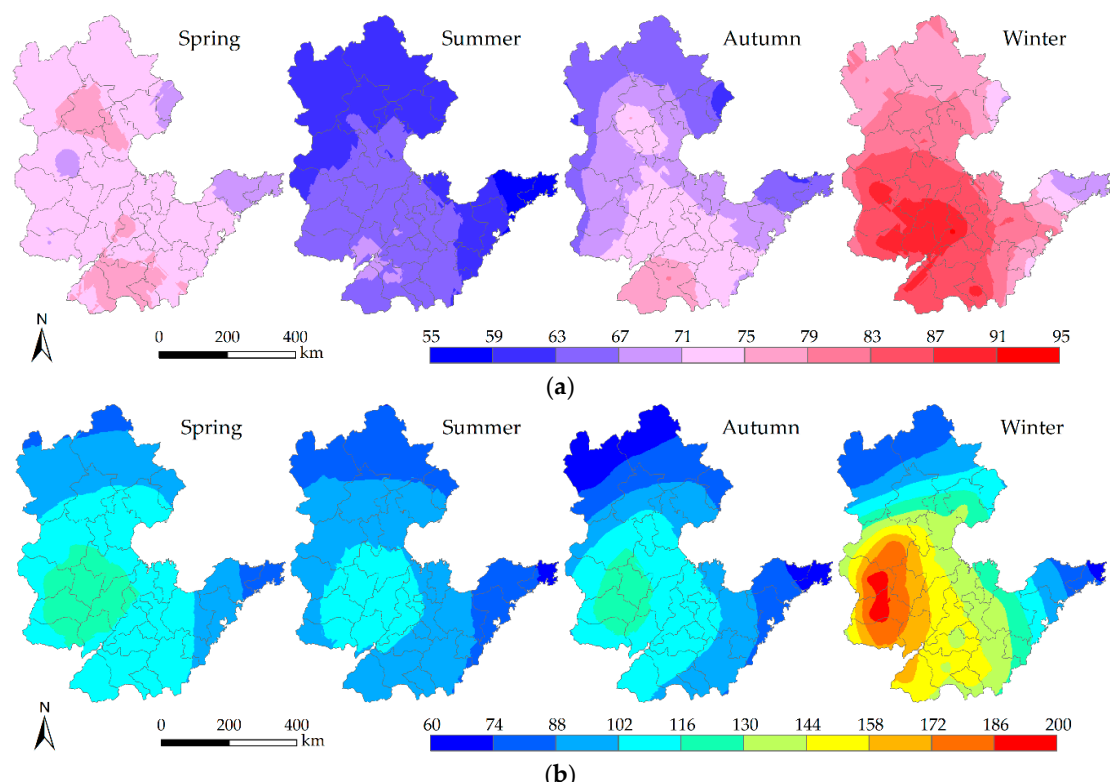

Figure 5. Spatial differentiation of air quality indices in different seasons. (a) Spatial variation characteristics of API in different seasons from 2008 to 2012, (b) Spatial variation characteristics of AQI in different seasons from 2013 to 2018.
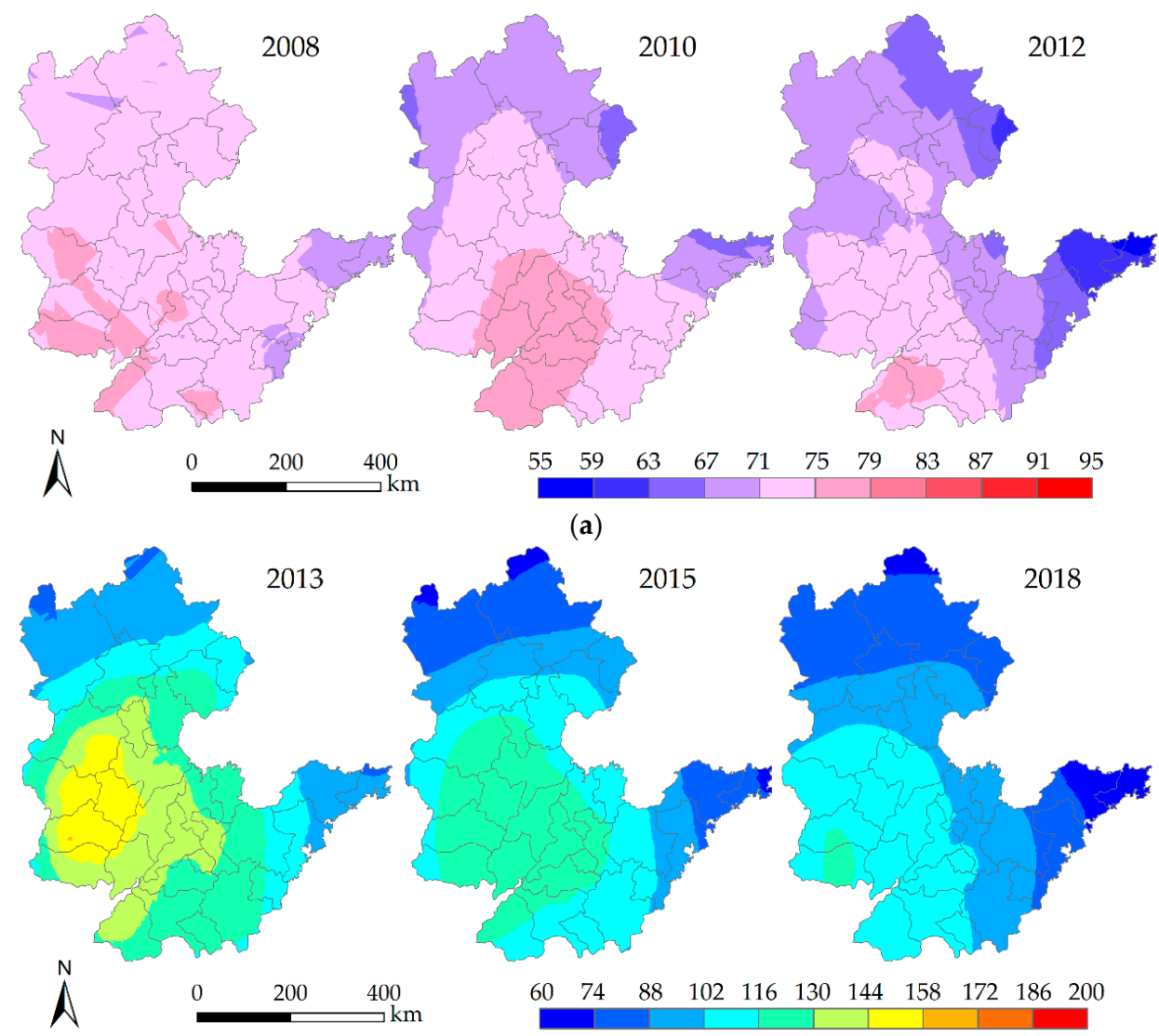

(a)

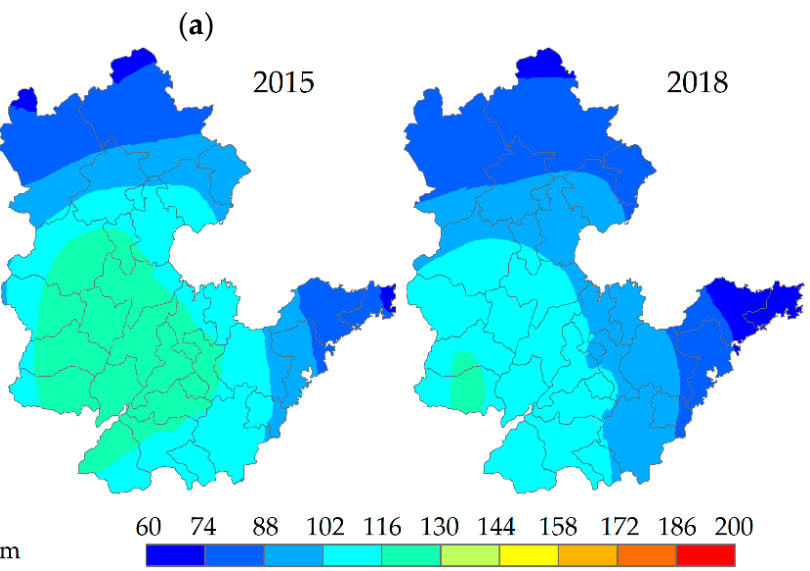

(b)

Figure 6. Spatial variation of air quality indices in different years. (a) Spatial variation pattern of API for the years 2008, 2010, and 2012, (b) Spatial variation pattern of AQI for the years 2013, 2015 and 2018. 


\subsection{Centroid Migration Route and Spatial Distribution Pattern of Air Quality}

The route and parameters of centroid migration of API and AQI are displayed in Figure 7 and Table 5, respectively. From 2008 to 2018, the centroid of API and AQI in NCCEZ showed a trend of southwest migration. The centroid of API and AQI in Hebei shifted southward, with a migratory distance of $65 \mathrm{~km}$, and it tended to the southwest in Shandong, with a migratory distance of $22 \mathrm{~km}$. The change of centroid of API and AQI in Beijing and Tianjin was not obvious, and showed the fluctuation between the north and the south, with a migratory distance of $12 \mathrm{~km}$ and $3 \mathrm{~km}$, respectively. Overall, the centroid of API and AQI in the study area migrated inland, indicating that the air quality in the inland areas had improved gradually.

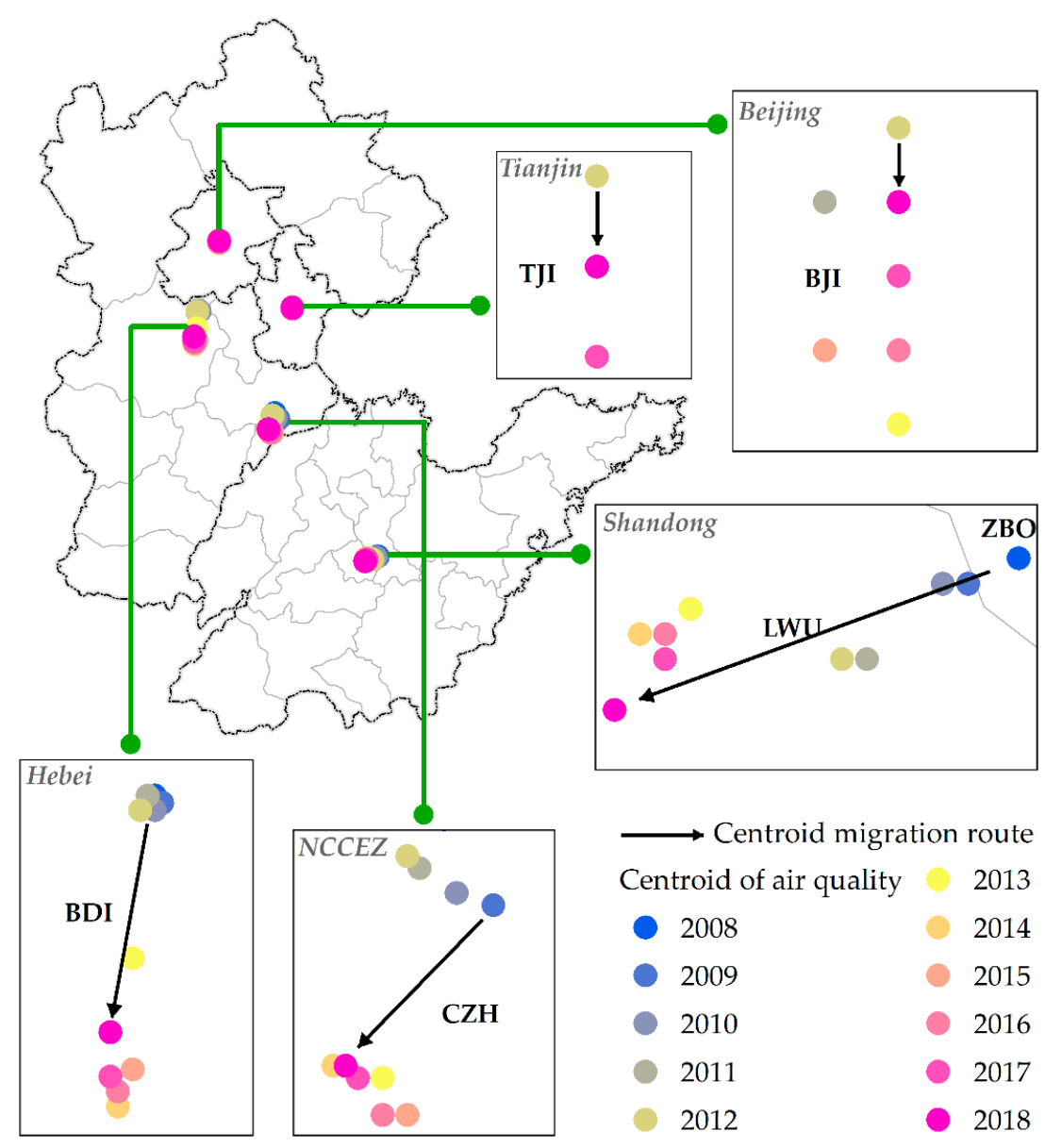

Figure 7. Centroid migration route of air quality indices from 2008 to 2018 (NCCEZ: the Northern Coastal Comprehensive Economic Zone, BDI: Baoding city, BJI: Beijing city, CZH: Cangzhou city, LWU: Laiwu city and TJI: Tianjin city).

Table 5. Detailed parameter information of centroid migration of air quality indices.

\begin{tabular}{|c|c|c|c|c|c|c|c|c|c|}
\hline \multirow{2}{*}{ Municipality or Province } & \multicolumn{3}{|c|}{ Migratory Distance (km) } & \multicolumn{3}{|c|}{ Migratory Direction } & \multicolumn{3}{|c|}{ Centroid Location } \\
\hline & $a^{*}$ & $\mathbf{b}^{*}$ & $c^{*}$ & $a^{*}$ & $\mathbf{b}^{*}$ & $c^{*}$ & $a^{*}$ & $\mathbf{b}^{*}$ & $c^{*}$ \\
\hline Beijing & 7 & 5 & 12 & South & North & South & - & - & - \\
\hline Hebei & 27 & 37 & 65 & South & South & South & BDI & BDI & BDI \\
\hline Shandong & 15 & 7 & 22 & Southwest & Southwest & Southwest & ZBO, LWU & LWU & $\mathrm{ZBO}, \mathrm{LWU}$ \\
\hline Tianjin & 1 & 2 & 3 & South & - & South & - & - & - \\
\hline NCCEZ & 38 & 18 & 57 & Southwest & Northwest & Southwest & $\mathrm{CZH}$ & $\mathrm{CZH}$ & $\mathrm{CZH}$ \\
\hline
\end{tabular}

* Note: a, b, and c denote the stage of 2008-2012, 2012-2018, and 2008-2018, respectively.

Figure 8 presents the global spatial autocorrelation results of air quality. The $I_{G}$ value of air quality indices ranged from 0.65 in 2008 to 0.76 in 2018, with a significance of $1 \%$, which indicated a 
positive significant spatial correlation. The value of $I_{G}$ displayed an upward trend in the study period, indicating that the spatial autocorrelation of air quality had strengthened gradually.

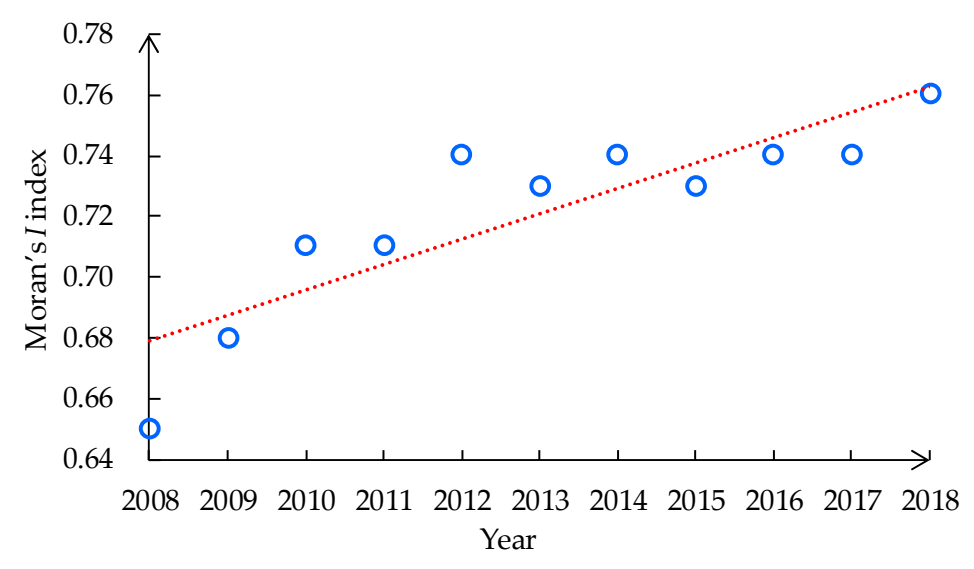

Figure 8. Change trend of global Moran's I index for air quality indices.

Figure 9 shows the spatial clustering pattern between each city and its neighboring cities in the NCCEZ over time. Most polluted cities were distributed in the west of Shandong province and the south of Hebei province, forming air pollution clusters. The cities with high air quality were located in the east of Shandong province and the north of Hebei province, suggesting that the air quality in these cities showed a favorable agglomeration. It is clear that there are no cities with poor air quality is surrounded by cities with good air quality, and that only one city with good air quality is surrounded by a city with poor air quality.

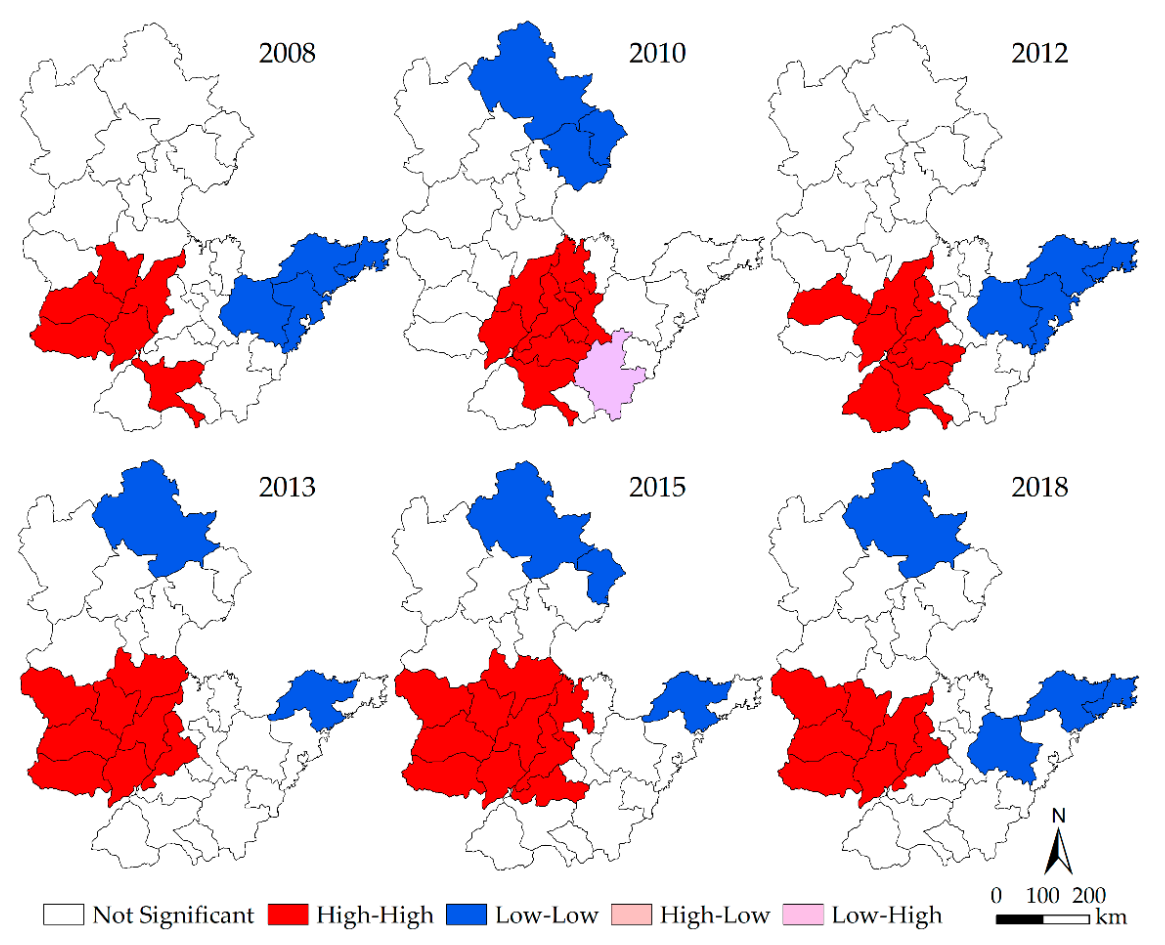

Figure 9. Pattern change of spatial clustering for API and AQI.

The values of the SPAEF were all greater than 0.6 and the Pearson correlation coefficients were all greater than 0.8 (Figure 10). It is indicated that the spatial distribution pattern of air quality in different years in the NCCEZ has a high correlation, which allegedly suggests that the air quality distribution pattern from 2008 to 2018 is relatively consistent. Comparing the CV ratio, it clear that the air quality 
has spatial variability from 2008 to 2018, which clarifies that there are differences in the distribution of air quality in the NCCEZ. The high histo matches clearly stress spatial details within the clusters of high air quality and poor air quality, revealing that there are more variations of air quality in several numerical intervals.
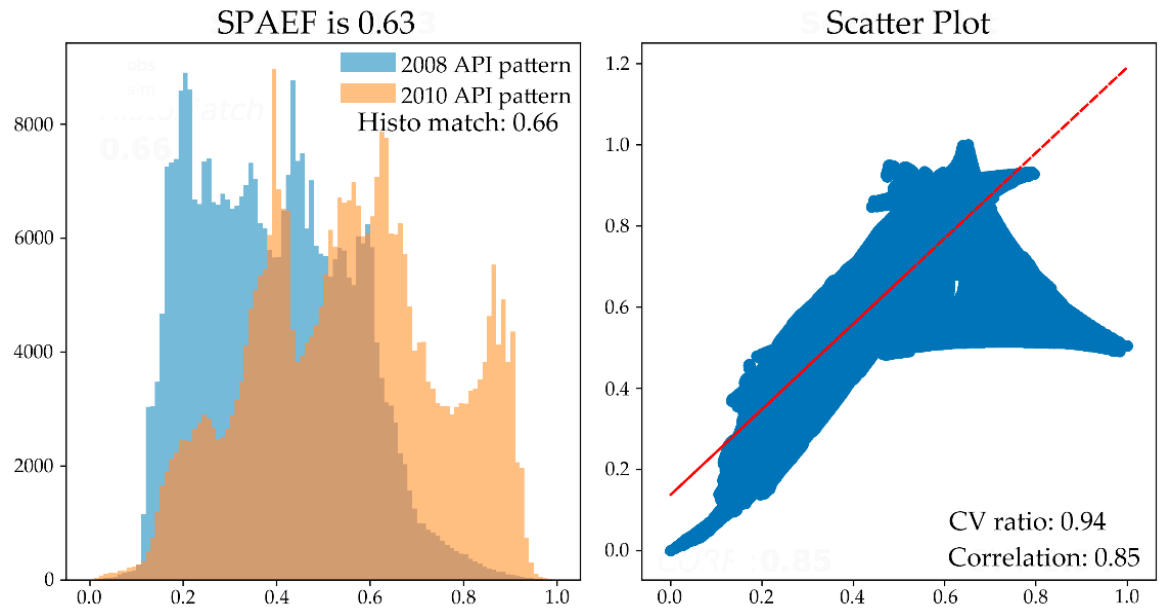

(a)
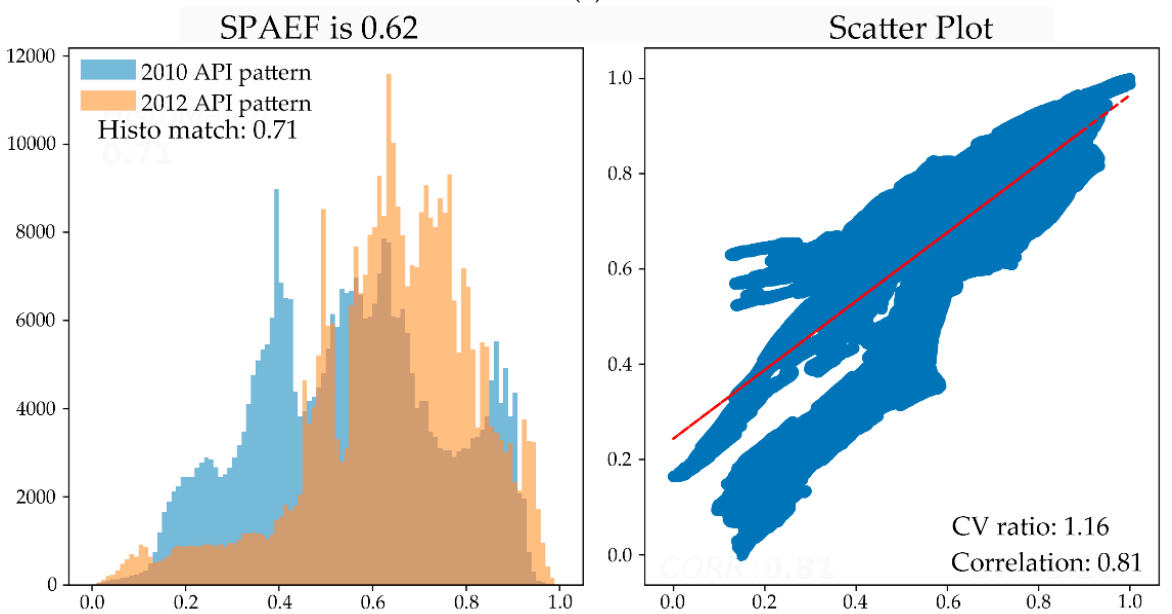

(b)
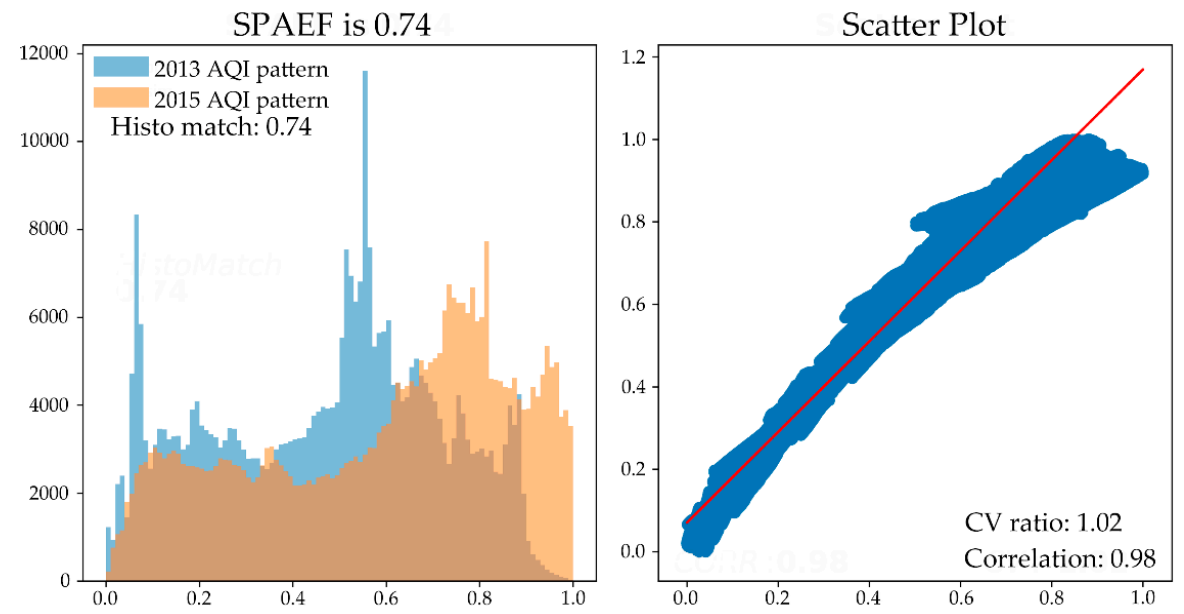

(c)

Figure 10. Cont. 

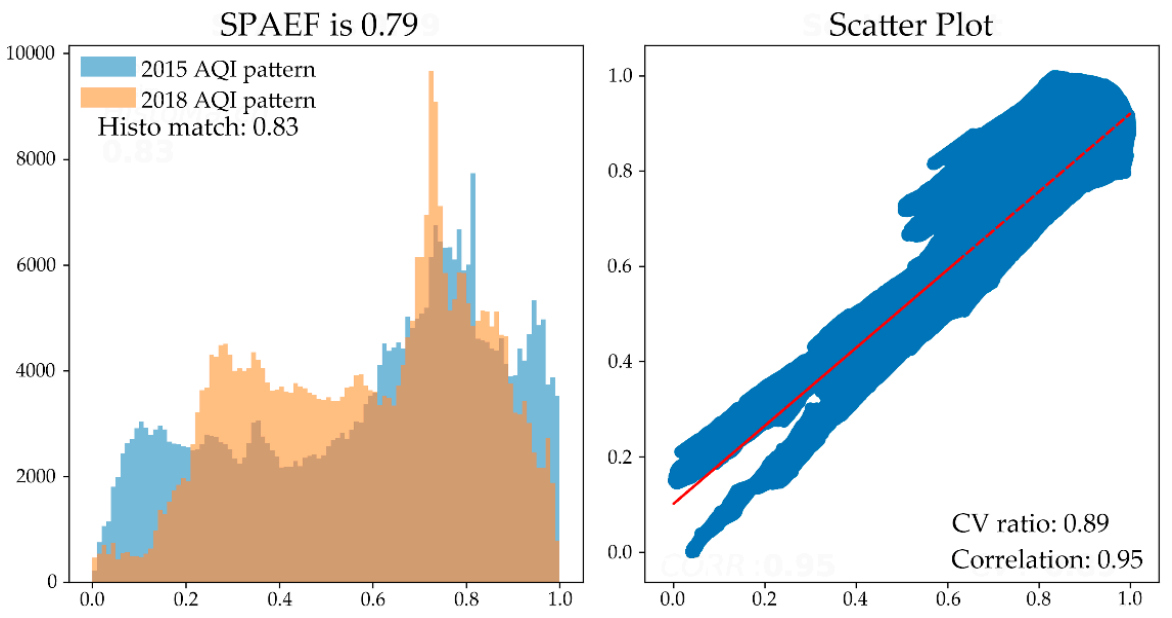

(d)

Figure 10. Comparison of spatial patterns for API and AQI. (a) Comparison of API spatial patterns between 2008 and 2010, (b) Comparison of API spatial patterns between 2010 and 2012, (c) Comparison of AQI spatial patterns between 2013 and 2015, (d) Comparison of AQI spatial patterns between 2015 and 2018.

\subsection{Change in the Type of Primary Pollutants}

Tables 6 and 7 depict changes in the type of primary pollutants in the NCCEZ. Between 2008 and 2012, $\mathrm{PM}_{10}$ was the dominant primary pollutant, occurring most frequently in the south of the study area. $\mathrm{SO}_{2}$ and $\mathrm{NO}_{2}$ formed a small proportion of the primary pollutants. The proportion of $\mathrm{PM}_{2.5}$ as the main primary pollutant was highest from 2013 to 2018. Cities with $\mathrm{PM}_{2.5}$ as the primary pollutant were mainly located in the southwest of the study area. The ratio of $\mathrm{O}_{3}$ and $\mathrm{PM}_{10}$ as the primary pollutants was the next most important. The cities with $\mathrm{O}_{3}$ and $\mathrm{PM}_{10}$ as the primary pollutant were mostly found in the southeast of the study area.

Table 6. Percentage of different primary pollutants for each city from 2008 to 2012.

\begin{tabular}{cccc}
\hline City & $\mathbf{N O}_{\mathbf{2}}$ & $\mathbf{P M}_{\mathbf{1 0}}$ & $\mathbf{S O}_{\mathbf{2}}$ \\
\hline BDI & - & 91.9 & 8.1 \\
BJI & - & 94.0 & 6.0 \\
HDA & - & 99.2 & 0.8 \\
JNA & - & 95.0 & 5.0 \\
JNI & 0.0 & 98.8 & 1.2 \\
QHD & - & 78.1 & 21.9 \\
LYI & - & 90.2 & 9.8 \\
RZH & 0.0 & 98.3 & 1.7 \\
SJZ & - & 88.5 & 11.5 \\
SJZ & 0.1 & 91.6 & 8.3 \\
TSH & - & 87.3 & 12.7 \\
TJI & - & 81.8 & 18.2 \\
WHA & - & 98.1 & 1.9 \\
WFA & 0.1 & 86.3 & 13.6 \\
YTA & - & 86.6 & 13.4 \\
ZZH & - & 93.3 & 6.7 \\
ZBO & - & 90.2 & 9.8 \\
\hline
\end{tabular}


Table 7. Percentage of different primary pollutants for each city from 2013 to 2018.

\begin{tabular}{|c|c|c|c|c|c|c|c|c|c|c|c|c|c|c|c|c|c|c|c|c|c|c|c|}
\hline City & $\mathrm{CO}$ & $\begin{array}{l}\mathrm{CO}, \\
\mathrm{O}_{3}\end{array}$ & $\mathrm{NO}_{2}$ & $\begin{array}{l}\mathrm{NO}_{2} \\
\mathrm{CO}\end{array}$ & $\begin{array}{c}\mathrm{NO}_{2} \\
\mathrm{O}_{3}\end{array}$ & $\begin{array}{l}\mathrm{NO}_{2,} \\
\mathrm{PM}_{10}\end{array}$ & $\begin{array}{c}\mathrm{NO}_{2,} \\
\mathrm{PM}_{10} \\
\mathrm{O}_{3}\end{array}$ & $\begin{array}{l}\mathrm{NO}_{2,} \\
\mathrm{PM}_{10} \\
\mathrm{PM}_{2.5}\end{array}$ & $\begin{array}{l}\mathrm{NO}_{2,} \\
\mathrm{PM}_{2.5}\end{array}$ & $\mathrm{O}_{3}$ & $\mathrm{PM}_{10}$ & $\begin{array}{c}\mathrm{PM}_{10} \\
\mathrm{CO}\end{array}$ & $\begin{array}{c}\mathrm{PM}_{10} \\
\mathrm{O}_{3}\end{array}$ & $\begin{array}{l}\mathbf{P M}_{10} \\
\mathrm{PM}_{2.5}\end{array}$ & $\begin{array}{c}\mathbf{P M}_{10} \\
\mathbf{P M}_{2.5} \\
\mathrm{O}_{3}\end{array}$ & $\mathrm{PM}_{2.5}$ & $\begin{array}{c}\mathbf{P M}_{2.5} \\
\mathrm{CO}\end{array}$ & $\begin{array}{c}\mathrm{PM}_{2.5} \\
\mathrm{O}_{3}\end{array}$ & $\mathrm{SO}_{2}$ & $\begin{array}{l}\mathrm{SO}_{2} \\
\mathrm{NO}_{2}\end{array}$ & $\begin{array}{l}\mathrm{SO}_{2} \\
\mathrm{PM}_{10}\end{array}$ & $\begin{array}{c}\mathrm{SO}_{2,} \\
\mathrm{PM}_{10} \\
\mathrm{PM}_{2.5}\end{array}$ & $\begin{array}{c}\mathrm{SO}_{2,} \\
\mathrm{PM}_{2.5}\end{array}$ \\
\hline BDI & - & - & 2.6 & - & - & 0.2 & - & - & 0.1 & 26.1 & 20.5 & - & 0.2 & 0.9 & - & 49.3 & - & 0.1 & 0.1 & - & - & - & - \\
\hline BJI & 0.2 & - & 12.1 & - & 0.1 & 0.2 & - & - & 0.2 & 29.6 & 12.3 & - & 0.1 & 0.2 & - & 44.9 & - & 0.1 & - & - & - & - & - \\
\hline BZH & 1.4 & - & 2.7 & - & - & 0.1 & - & 0.1 & 0.2 & 21.0 & 19.9 & - & 0.1 & 0.7 & - & 53.2 & - & - & 0.6 & - & 0.1 & - & 0.1 \\
\hline CZH & 0.1 & - & 5.9 & - & - & 0.2 & - & - & 0.1 & 30.8 & 17.5 & - & 0.1 & 0.9 & - & 44.1 & - & 0.2 & 0.1 & - & - & - & - \\
\hline $\mathrm{CDE}$ & - & - & 2.0 & - & - & 0.2 & - & - & 0.1 & 38.0 & 43.7 & - & 0.3 & 1.0 & - & 14.7 & - & - & - & - & - & - & - \\
\hline DZH & 0.2 & - & 1.1 & - & - & 0.3 & - & - & 0.1 & 27.1 & 22.0 & - & 0.2 & 0.5 & 0.1 & 48.3 & - & 0.1 & 0.2 & - & - & - & - \\
\hline DYI & - & - & 3.2 & - & - & 0.1 & - & 0.1 & 0.1 & 38.7 & 21.2 & - & 0.6 & 0.8 & 0.1 & 34.8 & - & 0.2 & 0.3 & - & - & - & - \\
\hline HDA & 0.1 & - & 2.7 & - & - & 0.2 & - & - & 0.1 & 18.3 & 29.1 & 0.1 & 0.3 & 1.6 & - & 47.5 & - & - & 0.1 & - & - & - & - \\
\hline HZE & 0.1 & - & 0.2 & - & - & - & - & - & - & 27.8 & 23.3 & - & 0.3 & 0.5 & - & 47.9 & - & - & - & - & - & - & - \\
\hline HSH & - & - & 1.0 & - & - & 0.1 & - & - & 0.1 & 26.1 & 23.2 & - & 0.2 & 1.2 & 0.1 & 48.0 & - & - & 0.1 & - & - & - & - \\
\hline JNA & - & - & 2.7 & - & - & 0.4 & - & - & - & 27.6 & 32.0 & - & 0.2 & 1.1 & - & 35.8 & - & - & 0.2 & - & - & - & - \\
\hline JNI & - & - & 1.8 & - & - & 0.1 & - & - & - & 32.8 & 25.3 & - & 0.3 & 1.1 & - & 38.5 & - & - & 0.1 & - & - & - & - \\
\hline LWU & - & - & 1.0 & - & - & - & - & 0.1 & 0.1 & 23.2 & 21.9 & - & 0.2 & 0.2 & - & 52.6 & - & - & 0.7 & - & - & - & - \\
\hline LFA & - & - & 10.4 & - & 0.2 & 0.2 & - & - & 0.3 & 28.4 & 19.2 & - & 0.0 & 0.6 & - & 40.6 & - & 0.1 & - & - & - & - & - \\
\hline LCH & - & - & 1.0 & - & - & 0.2 & - & - & - & 22.5 & 24.6 & - & 0.2 & 0.9 & - & 50.0 & - & 0.1 & 0.4 & 0.1 & - & 0.1 & 0.1 \\
\hline LYI & - & - & 0.9 & - & - & 0.1 & - & - & - & 28.2 & 33.9 & - & 0.2 & 1.3 & - & 35.1 & - & - & 0.1 & - & - & - & - \\
\hline QHD & 0.1 & - & 20.2 & 0.1 & 0.1 & 0.6 & 0.1 & 0.1 & 0.2 & 21.7 & 29.1 & - & 0.2 & 0.8 & - & 26.3 & - & 0.1 & 0.3 & - & 0.1 & - & - \\
\hline QDA & - & - & 5.8 & - & - & 0.1 & - & - & - & 37.2 & 30.2 & - & 1.4 & 1.2 & - & 24.1 & - & - & - & - & - & - & - \\
\hline RZH & - & - & 2.3 & - & 0.1 & 0.2 & - & 0.1 & - & 33.5 & 26.1 & - & 0.3 & 0.9 & 0.1 & 36.4 & - & 0.1 & - & - & - & - & - \\
\hline SJZ & - & - & 4.6 & - & - & 0.1 & - & - & - & 18.6 & 27.1 & - & 0.1 & 1.5 & 0.1 & 47.8 & - & - & 0.2 & - & - & - & - \\
\hline TAN & 0.1 & - & 1.0 & - & - & 0.2 & - & - & 0.1 & 32.3 & 24.2 & - & 0.2 & 1.2 & - & 40.8 & - & - & 0.1 & - & - & - & - \\
\hline TSH & 0.8 & 0.1 & 11.8 & 0.1 & - & 0.5 & 0.1 & 0.2 & 0.3 & 21.0 & 20.0 & - & 0.1 & 0.7 & 0.1 & 43.9 & 0.1 & - & 0.3 & - & 0.1 & - & - \\
\hline TJI & - & - & 11.0 & - & 0.1 & 0.2 & - & - & 0.5 & 23.3 & 18.6 & - & 0.3 & 0.6 & - & 45.0 & - & 0.1 & 0.4 & - & - & - & - \\
\hline WHA & - & - & 0.5 & - & - & 0.2 & - & - & - & 56.9 & 20.1 & - & 0.4 & 0.9 & - & 20.8 & - & 0.2 & 0.1 & - & - & - & - \\
\hline WFA & - & - & 0.1 & - & - & - & - & - & - & 35.7 & 29.9 & - & 0.4 & 0.9 & 0.1 & 32.6 & - & - & 0.2 & - & 0.2 & - & - \\
\hline XTA & - & - & 3.5 & - & 0.1 & 0.2 & - & - & 0.1 & 18.3 & 28.2 & - & 0.3 & 1.2 & - & 47.8 & - & 0.2 & 0.1 & 0.1 & - & - & - \\
\hline YTA & - & - & 5.0 & - & 0.1 & 0.3 & 0.1 & - & 0.3 & 41.9 & 25.1 & - & 0.6 & 0.7 & - & 26.0 & - & 0.1 & - & - & - & - & - \\
\hline $\mathrm{ZZH}$ & - & - & 0.1 & - & - & - & - & - & - & 29.9 & 28.2 & - & 0.2 & 1.4 & - & 40.2 & - & - & - & - & - & - & - \\
\hline ZJK & - & - & 1.6 & - & - & 0.1 & - & - & 0.1 & 47.2 & 39.6 & - & 0.6 & 0.4 & - & 7.4 & - & - & 2.8 & - & 0.3 & - & - \\
\hline ZBO & 0.2 & - & 2.4 & - & - & 0.5 & - & - & 0.1 & 28.7 & 23.8 & - & 0.4 & 1.0 & 0.1 & 41.8 & - & - & 1.1 & - & 0.1 & - & 0.1 \\
\hline
\end{tabular}




\subsection{Estimation of Spatial Econometric Models}

As shown in Table 8, it is noteworthy that, with statistical significance at the $1 \%$ level, the LM test and robust LM test estimations based on the SLM and SEM model were all significant. The test results of SLM were more significant than those of SEM, so SLM was selected to investigate the spatial relationship between air quality and natural as well as anthropogenic influence factors.

Table 8. Results of LM test and robust LM test.

\begin{tabular}{ccc}
\hline Item & API & AQI \\
\hline LM lag & 149.81 & 238.39 \\
robust LM lag & 47.99 & 44.21 \\
LM error & 115.96 & 200.39 \\
robust LM error & 14.14 & 6.21 \\
\hline
\end{tabular}

Note: all statistic results in the table are with a significance of $1 \%$.

The estimation results of SLM are reported in Table 9. From 2008 to 2012, two anthropogenic factors had significant negative effects on air quality, i.e., population and energy consumption. From the point of view of natural factors, temperature and atmospheric pressure were significantly negatively correlated with air quality. In contrast, wind speed and air quality showed a significant positive correlation. From 2013 to 2018, in terms of anthropogenic factors, air quality was significantly negatively correlated with population, the ratio of secondary industry, civilian car ownership, and energy consumption. There was a significant positive correlation between air quality and GDP. In terms of natural factors, temperature and atmospheric pressure had significant negative effects on air quality, while wind speed had significant positive effects.

Table 9. Estimation results of the influence factors of air quality from 2008 to 2018 based on the spatial lag model (SLM) model.

\begin{tabular}{|c|c|c|c|c|c|}
\hline \multirow{2}{*}{\multicolumn{2}{|c|}{ Independent Variable }} & \multirow{2}{*}{\multicolumn{2}{|c|}{$\begin{array}{c}\text { API } \\
\text { Coefficient Value }\end{array}$}} & \multirow{2}{*}{\multicolumn{2}{|c|}{$\frac{\text { AQI }}{\text { Coefficient Value }}$}} \\
\hline & & & & & \\
\hline \multirow{7}{*}{$\begin{array}{l}\text { Anthropogenic } \\
\text { factors }\end{array}$} & Constant & 0.1647 & & -0.5156 & $* * *$ \\
\hline & Population & 0.0183 & $* * *$ & 0.0806 & $* * *$ \\
\hline & $\begin{array}{c}\text { Urban land } \\
\text { area }\end{array}$ & -0.0130 & & -0.0376 & \\
\hline & GDP & 0.0076 & & -0.0557 & $* * *$ \\
\hline & $\begin{array}{l}\text { Ratio of } \\
\text { secondary } \\
\text { industry }\end{array}$ & -0.0113 & & 0.1041 & $* * *$ \\
\hline & $\begin{array}{l}\text { Civilian car } \\
\text { ownership }\end{array}$ & -0.0039 & & 0.0618 & $* * *$ \\
\hline & $\begin{array}{c}\text { Energy } \\
\text { consumption }\end{array}$ & 0.0058 & * & 0.0252 & $* * *$ \\
\hline \multirow{7}{*}{ Natural factors } & Constant & 0.5778 & $* * *$ & 0.9876 & $* * *$ \\
\hline & Elevation & -0.0021 & & -0.0131 & \\
\hline & Wind speed & -0.0593 & $* * *$ & -0.3110 & $* * *$ \\
\hline & Precipitation & 0.0211 & & -0.0549 & \\
\hline & Temperature & 0.0249 & * & 0.1742 & $* * *$ \\
\hline & $\begin{array}{c}\text { Atmospheric } \\
\text { pressure }\end{array}$ & 0.0156 & * & 0.0577 & $* *$ \\
\hline & NDVI & 0.0120 & & -0.0249 & \\
\hline
\end{tabular}

Note: ${ }^{*}$ indicates significance under $10 \%,{ }^{* *}$ indicates significance under $5 \%,{ }^{* * *}$ indicates significance under $1 \%$. 


\section{Discussion}

\subsection{Positive Effects of Air Pollution Control}

As the hazards of air pollution have become more widely recognized, the Chinese government has implemented a series of air pollution protection measures aimed at reducing air pollutants and improving air quality [48-50]. A summary of all critical air pollution control plans, policies, and regulations is presented in Figure 11. Early efforts, such as the national Five-Year Plans, which focused on economic restructuring to reduce air pollutant emissions, mainly addressed large point sources in the power and industry sectors, as they were responsible for major shares of total emissions [51]. Other government-mandated measures involved the application of state-of-the-art "clean" production technologies to replace fossil fuels and facilitating the development of clean energy, such as wind and solar power. In contrast to the significant reduction of air pollutant emissions from power and industry sectors, emissions from vehicles have increased in recent years [52]. Previous studies have confirmed that air pollution in Chinese megacities was directly associated with increasing vehicular traffic $[53,54]$. To reduce vehicle emissions, the government has implemented systemic emission control policies, including execution of emission standards for new vehicles, emission controls for in-use vehicles, improvement of fuel quality, promotion of sustainable transport, use of alternative fuels and advanced vehicles, and traffic management programs [55]. In recent years, China has held some very important events, which temporarily implemented more stringent air pollution control regulations to guarantee short-term air quality. The Asia-Pacific Economic Cooperation Meeting in 2014 and the Victory Day Parade (V-day Parade) in 2015 are two representative events, achieving air quality improvements through control strategies, such as temporary closure of many factories [56]. Successive implementation of the plans, policies and regulations has achieved an overall improvement of air quality. Our results showed that the annual average API and AQI of the NCCEZ generally decreased from 2008 to 2012 and from 2013 to 2018, respectively (Figure 4). In 2015, the government introduced a series of measures to control air pollution, which can be seen in the dramatic decline in AQI from 2014 to 2015 (Figure 4). Therefore, it can be inferred that, because of the implementation of policies and measures for air pollution control, the air quality has improved.

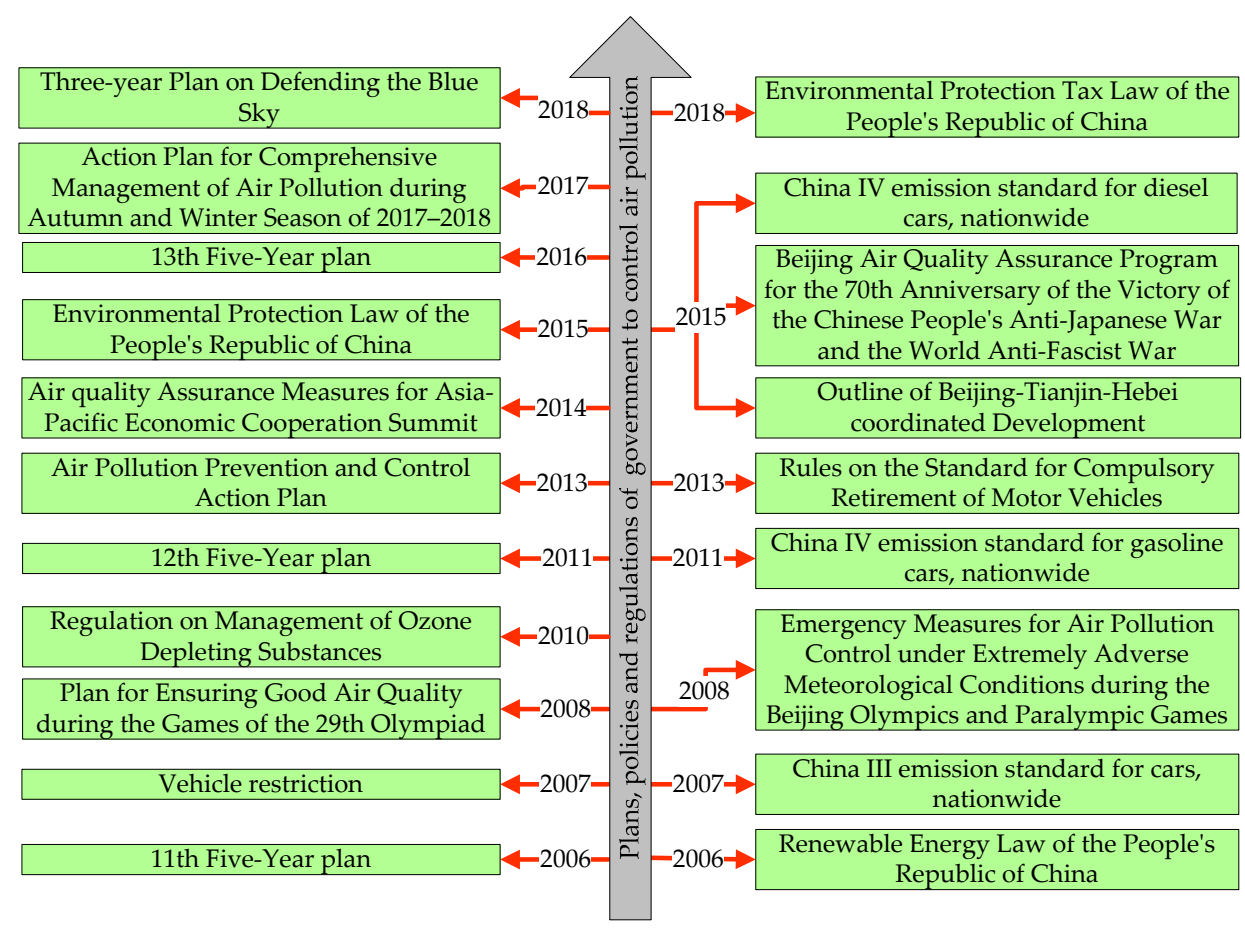

Figure 11. Plans, policies, and regulations of government to control air pollution. 


\subsection{Effect of Natural and Anthropogenic Factors on Air Quality}

Air pollution is a problem for human life and economic production: it is affected by both anthropogenic factors and natural factors [57,58]. In terms of anthropogenic factors, previous studies have shown that the population plays an important episodic role in causing air pollution [59]. With the increasing number of people, their needs for material goods have risen, resulting in an increase in air pollutant emissions in production and lifestyles. It can be inferred that because there are many human activities in populated areas, the population has a negative effect on air quality, which is consistent with our research (Table 9). Moreover, the increase in population has increased the consumption of cars to some extent, and more cars will lead to more exhaust emissions, resulting in a further deterioration of air quality. When the combustion of gasoline and diesel is not complete, the air quality becomes worse. This probably explains why the civilian car ownership had no crucial impact on air quality from 2008 to 2012, while from 2013 to 2018, it has significantly contributed to air pollution in the NCCEZ (Table 9). The increasing population has also increased the pressure on energy consumption. Production and use of energy, especially in unregulated, poorly regulated or inefficient energy consumption, is the most important source of air pollutant emissions $[60,61]$. Nearly $85 \%$ of the particulate matter and almost all the oxysulfide and oxynitride come from energy consumption. The proportion of coal consumption in the energy consumption structure remained stubbornly high. The leading industry in the southern cities of the study area is a high pollution industry dominated by iron and steel. Coal consumption accounts for a high proportion of energy consumption, and the structure of energy consumption is excessive in the south of the NCCEZ. As found in our study, the southern cities in the NCCEZ not only have poor air quality compared with other cities but also show air pollution agglomeration (Figures 6 and 9). Particulate matter $\left(\mathrm{PM}_{2.5}\right.$ and $\left.\mathrm{PM}_{10}\right)$ are also regarded as the main primary pollutant (Tables 6 and 7). Most cities still use central coal-fired heating in the winter, which leads to significantly worse air quality in winter than in other seasons. Our results confirm that the air quality in the NCCEZ is poor in winter (Figure 3). It is worth noting that the secondary industry emits a large number of pollutants due to its dependence on fossil fuels such as coal, resulting in increased air pollution. In recent years, the secondary industry in the NCCEZ has developed rapidly, showing a significant boost to the deterioration of air quality. However, with air pollution sweeping across China in 2013, threatening people's lives, health and socio-economic development, there has been raised awareness of environmental protection and increased air quality requirements [62]. The increase in revenue has given the government sufficient funds for the control of air pollution. After 2013, the government also issued a series of policies to improve air quality. From the model estimation results in our study, the GDP of the NCCEZ has a significant effect on the improvement of air pollution after 2013 (Table 9).

The air quality exhibited seasonal and regional variation and was strongly affected by variability in natural factors [63]. Wind speed is an important feature reflecting the dynamic stability of the atmosphere, which plays an important role in the diffusion, dilution and three-dimensional transport of air pollutants [64]. In spring, Asian dust storms are carried eastward by prevailing winds and pass over the NCCEZ, declining air quality. However, the inflow of comparatively clean maritime air in the summer prevailing winds is beneficial for air quality, particularly in coastal areas. In the coastal areas of the NCCEZ, the air quality was much better than that in other areas and showed the concentration of good air quality between cities (Figures 6 and 9). It should also be noted that due to the spatial correlation characteristics of atmospheric activity lead to significant spatial autocorrelation for air pollution [65], and there is no HL and only one LH in the study area (Figure 9). Unlike wind speed, the correlation between temperature and air quality varied according to regional conditions. A negative correlation usually occurred when increasing temperatures resulted in faster $\mathrm{SO}_{2}$ oxidation to sulfate and carbonaceous aerosol accumulation, which in turn lead to increasing $\mathrm{PM}_{10}$ concentrations, particularly in cities where coal combustion was the main source of energy for heating [66]. This explains why, in the NCCEZ where heavy industry is developed, the correlation between the air quality and temperature shows a pattern inversion between seasons, which reflects a significant negative correlation (Table 9). In terms of atmospheric pressure, the vertical airflow near the ground rises 
under the control of low-pressure systems, which can accelerate the diffusion of air pollutants. The low-pressure systems may also bring precipitation and adsorb pollutant particles, thus alleviating air pollution. In contrast, under the control of high-pressure systems, the vertical airflow near the ground sinks, the atmosphere is stable, and the pollutants are not easy to spread, thus increasing the degree of air pollution. This shows a negative correlation between atmospheric pressure and air quality in the NCCEZ (Table 9). Vegetation has a strong role in dust removal and air purification. The increase of vegetation, the establishment of green ecological corridors and other measures can improve air quality and raise environmental comfort levels [67]. Yet, the air purification effect of vegetation cover in the NCCEZ was relatively weak, because the vegetation coverage is not sufficient, and the green space management and maintenance are not in place. As a result, NDVI had no significant effect on air quality in the NCCEZ (Table 9).

\subsection{Suggestions for Improving Air Quality}

Due to the arduous, complex and long-term nature of air pollution prevention and control work, the policy planners must consider various factors that affect air pollution to formulate and implement feasible measures. The results of this study can be used as a guideline for improving air quality.

First, due to differences in resource endowment, economic development level and air pollution causes for different cities, the government should adhere to regionally differentiated air pollution control policies. As the air quality in the winter is the worst (Figure 3), more attention should be paid to the adjustment of the energy consumption structure and the use of air purification approaches in winter.

Second, in view of the existence of significant spatial clustering (Figures 8 and 9), air pollution control is not a single fight in a single city. In order to achieve the goal of controlling complex air pollution and sharing governance results, it is necessary to break the boundaries of administrative cities. Air pollution mitigation should rely on regional cooperation, unify environmental regulation actions, and coordinate air pollution management.

Third, regarding the government, more rigorous regulations and laws should be passed to prevent and control air pollution. For the areas with serious air pollution, projects should be implemented to effectively control and alleviate the spread of pollution. In the study area, air pollution in southwestern cities was more serious (Figure 6). Therefore, more stringent air control measures should be implemented in these locations.

Fourth, in focusing on the importance of clean air, local managers and environmentalists should alleviate air pollution by imparting information to local residents about the prevention and control of air pollution and by disseminating knowledge about the severe threats posed by air pollution.

\subsection{Advantages and Limitations of the Study}

The analysis of air quality change characteristics in our study was conducted from a synthesized point of view instead of an isolated perspective. Through the comprehensive analysis of the spatio-temporal distribution pattern of API and AQI, the air pollution status of NCCEZ was accurately reflected. Moreover, using spatial econometric analysis better discerned which factors have an impact on air quality, and determined their relative effect on air quality, which provides a flexible, effective and labor-saving method for air pollution analysis.

In 2013, the air quality assessment index was changed from API to AQI, and most previous studies focused on the separate analysis of API or AQI, lacking continuity [68]. Our analysis focused on air quality spatio-temporal dynamics over a continuous time series (from 2008 to 2018). The results are of practical significance in comparison to previous studies. Furthermore, they can be applied to other cities or regions to analyze air quality variations.

However, this study has some limitations that should be noted. Due to the limited availability of data in the NCCEZ, only some of the natural and anthropogenic factors affecting air quality have been collected. Thus, there may be other factors affecting air quality that have not been analyzed. 
In future research, we will continue to collect relevant data to improve the study of influential factors on air pollution. Moreover, as a result of the lack of air quality data at different times in one day, the analysis of air quality changes on different days and times (a rush hour for example) cannot be carried out. In the study, only the variations of air quality in different months, seasons and years were analyzed, which would lead to ascertain difficultly the air quality changes in even fewer time-intervals and other potential influences of human activities and natural factors on air quality. Meanwhile, the time series of data for air quality analysis in the NCCEZ covered only the years from 2008 to 2018. Therefore, intensive studies of air pollution monitoring, including longer time sequences and smaller time intervals, need to be implemented in the future.

The spatial distribution of air quality monitoring stations is very important for the interpolation results. Different monitoring station locations would produce different interpolation results. Most of the monitoring stations in the NCCEZ are located in and around the center of the city, so there may be increased the overestimation possibility of air pollution. In addition, due to the sparse distribution of air quality monitoring stations, it is difficult to achieve higher precision estimation results. Therefore, in the further monitoring and assessment of air quality, increasing the number of air quality monitoring stations and setting them up uniformly in the space would provide desirable help for obtaining air quality distribution data with higher accuracy.

\section{Conclusions}

The analysis of air quality is essential to define air pollution dynamics as well as underpin knowledge-based conservation policies and funding decisions by government and managers. In this study, combining spatial analysis, centroid migration calculations, spatial autocorrelation analysis, and a spatial econometric model, we examined the spatio-temporal patterns of air quality and their driving factors in the NCCEZ from 2008 to 2018. Our results showed that the air quality had improved and the air quality of coastal areas was better than that of inland areas. The primary pollutants were $\mathrm{PM}_{2.5}$, $\mathrm{PM}_{10}$, and $\mathrm{O}_{3}$. Population, energy consumption, temperature and atmospheric pressure were found to exert a significant negative impact on air quality, while wind speed had a significant positive impact. The methods and results from this study can help our understanding of air quality changes and their driving forces. These conclusions can be used as a guide for government policies to effectively prevent and manage air pollution.

Author Contributions: Conceptualization, methodology, formal analysis, as well as writing-original draft preparation, review and editing, Y.S. and C.L.; software, X.L.; validation, L.Z.; investigation, Y.G.; resources, Y.L.; data curation and visualization, Y.S.; supervision, project administration and funding acquisition, C.L. All authors have read and agreed to the published version of the manuscript.

Funding: This research was jointly funded by the Social Science and Humanity on Young Fund of the Ministry of Education of China (No. 17YJCZH118) and the Science and Technology Innovation Foundation of Fujian Agriculture and Forestry University (NO. CXZX2016228).

Acknowledgments: We appreciate the air quality indices data provide by the Ministry of Ecology and Environment of the People's Republic of China (http://www.meegov.cn), as well as thank Leonie Seabrook, from Liwen Bianji, Edanz Group China (www.liwenbianji.cn/ac), for editing the English text of a draft of this manuscript. We also thank the National Earth System Science Data Center for providing geographic information data (http://www.geodata.cn).

Conflicts of Interest: The authors declare no conflict of interest.

\section{References}

1. World Health Organization. 7 Million Premature Deaths Annually Linked to Air Pollution. Available online: https://www.who.int/mediacentre/news/releases/2014/air-pollution/en/ (accessed on 26 March 2014).

2. Tao, P. American Legislation Experience of the Management of City Air Pollution. Urban. Dev. Stud. 2015, 22, 9-13, 24. (In Chinese)

3. Kumar, R.; Peuchm, V.; Crawford, J.; Brasseur, G. Five steps to improve air-quality forecasts. Nature 2018, 561, 27-29. [CrossRef] [PubMed] 
4. Matus, K.; Nam, K.; Selin, N.; Lamsal, L.; Reilly, J.; Paltsev, S. Health damages from air pollution in China. Glob. Environ. Chang. 2012, 22, 55-66. [CrossRef]

5. Silva, R.; West, J.; Zhang, Y.; Anenberg, S.; Lamarque, J.; Shindell, D.; Collins, W.; Dalsoren, S.; Faluvegi, G.; Folberth, G.; et al. Global premature mortality due to anthropogenic outdoor air pollution and the contribution of past climate change. Environ. Res. Lett. 2013, 8, 034005. [CrossRef]

6. Lelieveld, J.; Evans, J.; Fnais, M.; Giannadaki, D.; Pozzer, A. The contribution of outdoor air pollution sources to premature mortality on a global scale. Nature 2015, 525, 367-371. [CrossRef]

7. Mirabelli, M.; Boehmer, T.; Damon, S.; Sircar, K.; Wall, H.; Yip, F.; Zahran, H.; Garbe, P. Air quality awareness among US adults with respiratory and heart disease. Am. J. Prev. Med. 2018, 54, 679-687. [CrossRef]

8. An, R.; Yu, H. Impact of ambient fine particulate matter air pollution on health behaviors: A longitudinal study of university students in Beijing, China. Public. Health. 2018, 159, 107-115. [CrossRef] [PubMed]

9. Saberian, S.; Heyes, A.; Rivers, N. Alerts Work! Air Quality Warnings and Cycling. Resour. Energy. Econ. 2017, 49, 165-185. [CrossRef]

10. Organization for Economic Co-operation and Development. Air Pollution to Cause 6-9 Million Premature Deaths and Cost 1\% GDP by 2060. Available online: http://www.oecd.org/environment/air-pollution-tocause-6-9-million-premature-deaths-and-cost-1-gdp-by-2060.htm (accessed on 6 September 2016).

11. Wang, H.; Xu, J.; Zhang, M.; Yang, Y.; Shen, X.; Wang, Y.; Chen, D.; Guo, J. A study of the meteorological causes of a prolonged and severe haze episode in January 2013 over central-eastern China. Atmos. Environ. 2014, 98, 146-157. [CrossRef]

12. Querol, X.; Alastuey, A.; Ruiz, C.; Artiñano, B.; Hansson, H.; Harrison, R.; Buringh, E.; Brink, H.; Lutz, M.; Bruckmann, P.; et al. Speciation and origin of $\mathrm{PM}_{10}$ and $\mathrm{PM}_{2.5}$ in selected European cities. Atmos. Environ. 2004, 38, 6547-6555. [CrossRef]

13. Qu, Y.; An, J.; Li, J.; Chen, Y.; Li, Y.; Liu, X.; Hu, M. Effects of $\mathrm{NO}_{\mathrm{x}}$ and VOCs from five emission sources on summer surface $\mathrm{O}_{3}$ over the Beijing-Tianjin-Hebei region. Adv. Atmos. Sci. 2014, 31, 787-800. [CrossRef]

14. Diapouli, E.; Manousakas, M.; Vratolis, S.; Vasilatou, V.; Maggos, T.; Saraga, D.; Grigoratos, T.; Argyropoulos, G.; Voutsa, D.; Samara, C.; et al. Evolution of air pollution source contributions over one decade, derived by $\mathrm{PM}_{10}$ and $\mathrm{PM}_{2.5}$ source apportionment in two metropolitan urban areas in Greece. Atmos. Environ. 2017, 164, 416-430. [CrossRef]

15. Chu, H.; Huang, B.; Lin, C. Modeling the spatio-temporal heterogeneity in the $\mathrm{PM}_{10}-\mathrm{PM}_{2.5}$ relationship. Atmos. Environ. 2015, 102, 176-182. [CrossRef]

16. Zhao, H.; Zheng, Y.; Li, C. Spatiotemporal Distribution of $\mathrm{PM}_{2.5}$ and $\mathrm{O}_{3}$ and Their Interaction during the Summer and Winter Seasons in Beijing, China. Sustainability 2018, 10, 4519. [CrossRef]

17. Ozkurt, N.; Sari, D.; Akalin, N.; Hilmioglu, B. Evaluation of the impact of $\mathrm{SO}_{2}$ and $\mathrm{NO}_{2}$ emissions on the ambient air-quality in the Çan-Bayramiç region of northwest Turkey during 2007-2008. Sci. Total Environ. 2013, 456, 254-266. [CrossRef]

18. Robichaud, A.; Ménard, R.; Zaïtseva, Y.; Anselmo, D. Multi-pollutant surface objective analyses and mapping of air quality health index over North America. Air Qual. Atmos. Health 2016, 9, 743-759. [CrossRef]

19. Ye, W.; Ma, Z.; Ha, X.; Yang, H.; Weng, Z. Spatiotemporal patterns and spatial clustering characteristics of air quality in China: A city level analysis. Ecol. Indic. 2018, 91, 523-530. [CrossRef]

20. Zhu, S.; Horne, J.; Mac Kinnon, M.; Samuelsen, G.; Dabdub, D. Comprehensively assessing the drivers of future air quality in California. Environ. Int. 2019, 125, 386-398. [CrossRef]

21. Bertazzon, S.; Shahid, R. Schools, Air Pollution, and Active Transportation: An Exploratory Spatial Analysis of Calgary, Canada. Int. J. Environ. Res. Public Health 2017, 14, 834. [CrossRef]

22. Chen, Z.; Xu, B.; Cai, J.; Gao, B. Understanding temporal patterns and characteristics of air quality in Beijing: A local and regional perspective. Atmos. Environ. 2016, 127, 303-315. [CrossRef]

23. Liu, H.; Fang, C.; Huang, J.; Zhu, X.; Zhou, Y.; Wang, Z.; Zhang, Q. The spatial-temporal characteristics and influencing factors of air pollution in Beijing-Tianjin-Hebei urban agglomeration. Acta Geogr. Sin. 2018, 73, 177-191. (In Chinese)

24. Yan, Y.; Li, Y.; Sun, M.; Wu, Z. Primary Pollutants and Air Quality Analysis for Urban Air in China: Evidence from Shangha. Sustainability 2019, 11, 2319. [CrossRef]

25. Parrish, D.; Xu, J.; Croes, B.; Shao, M. Air quality improvement in Los Angeles-Perspectives for developing cities. Front. Environ. Sci. Eng. 2016, 10, 11. [CrossRef] 
26. Wu, C.; Hu, W.; Zhou, M.; Li, S.; Jia, Y. Data-driven regionalization for analyzing the spatiotemporal characteristics of air quality in China. Atmos. Environ. 2019, 203, 172-182. [CrossRef]

27. Xu, W.; Sun, J.; Liu, Y.; Xiao, Y.; Tian, Y.; Zhao, B.; Zhang, X. Spatiotemporal variation and socioeconomic drivers of air pollution in China during 2005-2016. J. Environ. Manag. 2019, 245, 66-75. [CrossRef] [PubMed]

28. Ministry of Ecology and Environment of the People's Republic of China. Ambient Air Quality Standards. Available online: http://kjs.mee.gov.cn/hjbhbz/bzwb/dqhjbh/dqhjzlbz/199612/t19961206_67502. shtml (accessed on 1 October 2017).

29. Ministry of Ecology and Environment of the People's Republic of China. Ambient Air Quality Standards. Available online: http://kjs.mee.gov.cn/hjbhbz/bzwb/dqhjbh/dqhjzlbz/201203/t20120302_224165.shtml (accessed on 1 January 2016).

30. Michael, R.; Olenick, C.R.; Monaghan, A.J.; Wilhelmi, O.V.; Wiedinmyer, C.; Hayden, M.H.; Estes, M. Application of geostatistical approaches to predict the spatio-temporal distribution of summer ozone in Houston, Texas. J. Expo. Sci. Environ. Epidemiol. 2019, 29, 806-820. [CrossRef]

31. Wong, D.W.S.; Yuan, L.L.; Perlin, S.A. Comparison of spatial interpolation methods for the estimation of air quality data. J. Expo. Sci. Environ. Epidemiol. 2004, 14, 404-415. [CrossRef]

32. Cheng, Y.; You, L.; Zhu, Y.; Ma, S. Climate season division and its application in Chifeng region. J. Arid Land Resour. Environ. 2017, 31, 171-177. (In Chinese)

33. Liu, H.; Fang, C.; Zhang, X.; Wang, Z.; Bao, C.; Li, F. The effect of natural and anthropogenic factors on haze pollution in Chinese cities: A spatial econometrics approach. J. Clean. Prod. 2017, 165, 323-333. [CrossRef]

34. Bai, L.; Jiang, L.; Zhou, H.; Chen, Z. Spatio-temporal Characteristics of Air Quality Index and Its Driving Factors in the Yangtze River Economic Belt: An Empirical Study Based on Bayesian Spatial Econometric Model. Sci. Geogr. Sin. 2018, 38, 2100-2108. (In Chinese)

35. Xiao, Y.; Tian, Y.; Xu, W.; Liu, J.; Wan, Z.; Zhang, X.; Liu, X. Study on the spatiotemporal characteristics and socioeconomic driving factors of air pollution in China. Ecol. Environ. Sci. 2018, 27, 518-526. (In Chinese)

36. National Aeronautics and Space Administration. MODIS 'Vegetation Indices 16-Day L3 Global 250 m’ Product. Available online: https://ladsweb.modaps.eosdis.nasa.gov/search/ (accessed on 1 March 2019).

37. National Meteorological Information Center. China's Surface Climate Data Daily Value Dataset (V3.0). Available online: https:/data.cma.cn/data/cdcdetail/dataCode/SURF_CLI_CHN_MUL_DAY_V3.0.html (accessed on 1 March 2019).

38. National Bureau of Statistics of China. China Statistical Yearbook for Regional Economy 2009-2014; China Statistics Press: Beijing, China, 2014. (In Chinese)

39. National Bureau of Statistics of China. China Statistical Yearbook of Tertiary Industry 2015-2019; China Statistics Press: Beijing, China, 2019. (In Chinese)

40. National Bureau of Statistics of China. China City Statistical Yearbook 2009-2019; China Statistics Press: Beijing, China, 2019. (In Chinese)

41. Moran, P. The interpretation of statistical maps. J. R. Stat. Soc. B 1948, 10, 243-251. [CrossRef]

42. Anselin, L. Local Indicators of Spatial Association-LISA. Geogr. Anal. 1995, 27, 93-115. [CrossRef]

43. Koch, J.; Demirel, M.C.; Stisen, S. The SPAtial EFficiency metric (SPAEF): Multiple-component evaluation of spatial patterns for optimization of hydrological models. Geosci. Model Dev. 2018, 11, 1873-1886. [CrossRef]

44. Qiao, Z.; Huang, N.; Xu, X.; Sun, Z.; Wu, C.; Yang, J. Spatio-temporal pattern and evolution of the urban thermal landscape in metropolitan Beijing between 2003 and 2017. Acta Geogr. Sin. 2019, 74, 475-789. (In Chinese)

45. Huang, X.; Shao, T.; Zhao, J.; Cao, J.; Yue, D. Impact of meteorological factors and precursors on spatial distribution of ozone concentration in Eastern China. China. Environ. Sci. 2019, 39, 2273-2282. (In Chinese)

46. Hao, Y.; Liu, Y. The influential factors of urban $\mathrm{PM}_{2.5}$ concentrations in China: A spatial econometric analysis. J. Clean. Prod. 2016, 112, 1443-1453. [CrossRef]

47. Dong, K.; Hochman, G.; Kong, X.; Sun, R.; Wang, Z. Spatial econometric analysis of China's PM 10 pollution and its influential factors: Evidence from the provincial level. Ecol. Indic. 2019, 96, 317-328. [CrossRef]

48. Tian, Y.; Jiang, Y.; Liu, Q.; Xu, D.; Zhao, S.; He, L.; Liu, H.; Xu, H. Temporal and spatial trends in air quality in Beijing. Landscape. Landsc. Urban. Plan. 2019, 185, 35-43. [CrossRef]

49. Tilt, B. China's air pollution crisis: Science and policy perspectives. Environ. Sci. Policy 2019, 92, $275-280$. [CrossRef] 
50. Zeng, Y.; Cao, Y.; Qiao, X.; Seyler, B.; Tang, Y. Air pollution reduction in China: Recent success but great challenge for the future. Sci. Total Environ. 2019, 663, 329-337. [CrossRef] [PubMed]

51. Liu, J.; Kiesewetter, G.; Klimont, Z.; Cofala, J.; Heyes, C.; Schöppa, W.; Zhu, T.; Cao, G.; Gomez-Sanabria, A.; Sandera, R.; et al. Mitigation pathways of air pollution from residential emissions in the Beijing-Tianjin-Hebei region in China. Environ. Int. 2019, 125, 236-244. [CrossRef] [PubMed]

52. Guo, Y.; Wang, Z.; Kang, H.; Gu, C.; Wang, G.; Zang, X.; Ji, Y.; Li, M. Impact of automobile vehicles exhaust emissions on metropolitan air quality: Analysis study on the air pollution change before and after the Spring Festival in Urumqi City, China. Acta Sci. Circumst. 2014, 34, 1109-1117. (In Chinese)

53. Yang, F.; Tan, J.; Zhao, Q.; Du, Z.; He, K.; Ma, Y.; Duan, F.; Chen, G.; Zhao, Q. Characteristics of $\mathrm{PM}_{2.5}$ speciation in representative megacities and across China. Atmos. Chem. Phys. 2011, 11, 5207-5219. [CrossRef]

54. Cui, H.; Chen, W.; Dai, W.; Liu, H.; Wang, X.; He, K. Source apportionment of $\mathrm{PM}_{2.5}$ in Guangzhou combining observation data analysis and chemical transport model simulation. Atmos. Environ. 2015, 116, 262-271. [CrossRef]

55. Wu, X.; Wu, Y.; Zhang, S.; Liu, H.; Fu, L.; Hao, J. Assessment of vehicle emission programs in China during 1998-2013: Achievement, challenges and implications. Environ. Pollut. 2016, 214, 556-567. [CrossRef]

56. Li, X.; Qiao, Y.; Zhu, J.; Shi, L.; Wang, Y. The "APEC blue" endeavor: Causal effects of air pollution regulation on air quality in China. J. Clean. Prod. 2017, 168, 1381-1388. [CrossRef]

57. Lyu, Y.; Wang, C.; Cao, X. Ecological risk of urbanization and risk management. Acta. Ecol. Sin. 2018, 38, 359-370. (In Chinese)

58. Zhan, D.; Kwan, M.; Zhang, W.; Yu, X.; Meng, B.; Liu, Q. The driving factors of air quality index in China. J. Clean. Prod. 2018, 197, 1342-1351. [CrossRef]

59. Han, L.; Zhou, W.; Pickett, S.; Li, W.; Li, L. An optimum city size? The scaling relationship for urban population and fine particulate $\left(\mathrm{PM}_{2.5}\right)$ concentration. Environ. Pollut. 2016, 208, 96-101. [CrossRef]

60. Khan, M.; Zaman, K.; Irfan, D.; Awan, U.; Ali, G.; Kyophilavong, P.; Shahbaz, M.; Naseem, I. Triangular relationship among energy consumption, air pollution and water resources in Pakistan. J. Clean. Prod. 2016, 112, 1375-1385. [CrossRef]

61. Lyu, W.; Li, Y.; Guan, D.; Zhao, H.; Zhang, Q.; Liu, Z. Driving forces of Chinese primary air pollution emissions: An index decomposition analysis. J. Clean. Prod. 2016, 133, 136-144. [CrossRef]

62. Cheng, Y.; Liu, T.; Zhao, Y.; Wang, Y. Spatiotemporal Evolution and Socioeconomic Driving Mechanism of Air Quality in Beijing-Tianjin-Hebei and Surrounding Areas (“2+26"Cities). Econ. Geogr. 2019, 39, 183-192. (In Chinese)

63. Qiao, Z.; Wu, F.; Xu, X.; Yang, J.; Liu, L. Mechanism of Spatiotemporal Air Quality Response to Meteorological Parameters: A National-Scale Analysis in China. Sustainability 2019, 11, 3957. [CrossRef]

64. Xu, M.; Wang, J.; Ye, X.; Zhang, C.; Zhang, W. Variation characteristics of air pollution indexes of two cities in Hebei province. J. Environ. Health 2016, 33, 886-890. (In Chinese)

65. Cheng, Z.; Li, L.; Liu, J. Identifying the spatial effects and driving factors of urban $\mathrm{PM}_{2.5}$ pollution in China. Ecol. Indic. 2017, 82, 61-75. [CrossRef]

66. Tai, A.; Mickley, L.; Jacob, D. Correlations between fine particulate matter $\left(\mathrm{PM}_{2.5}\right)$ and meteorological variables in the United States: Implications for the sensitivity of $\mathrm{PM}_{2.5}$ to climate change. Atmos. Environ. 2010, 44, 3976-3984. [CrossRef]

67. De Carvalho, R.; Szlafszteinm, C. Urban vegetation loss and ecosystem services: The influence on climate regulation and noise and air pollution. Environ. Pollut. 2019, 245, 844-852. [CrossRef]

68. Xiao, Y.; Tian, Y.; Xu, W.; Wu, J.; Tian, L.; Liu, J. Spatiotemporal pattern changes of air quality in China from 2005 to 2015. Ecol. Environ. Sci. 2017, 26, 243-252. (In Chinese)

(C) 2020 by the authors. Licensee MDPI, Basel, Switzerland. This article is an open access article distributed under the terms and conditions of the Creative Commons Attribution (CC BY) license (http://creativecommons.org/licenses/by/4.0/). 